\title{
Enhanced Removal of Mercury and Lead by a Novel and Efficient Surface-functionalized Imogolite with Nanoscale Zero-valent Iron Material
}

Estefanía Martinis ( $\sim$ emartinis@mendoza-conicet.gob.ar)

CONICET: Consejo Nacional de Investigaciones Cientificas y Tecnicas

Juliano Denardin

CEDENNA

Raul Calderón Raul Calderón

Universidad Bernardo O'Higgins

Cristóbal Flores

Universidad de Santiago de Chile

Karen Manquián-Cerda

Universidad de Santiago de Chile

Tamara Maldonado

Universidad de Santiago de Chile

Nicolás Arancibia-Miranda

Universidad de Santiago de Chile

\section{Research Article}

Keywords: Imogolite, Nanoscale zero valent iron (nZVI), Hybrid material, Neurotoxic metals ( $\mathrm{Hg}$ and Pb) removal

Posted Date: May 28th, 2021

DOI: https://doi.org/10.21203/rs.3.rs-526809/v1

License: (9) This work is licensed under a Creative Commons Attribution 4.0 International License. Read Full License

Version of Record: A version of this preprint was published at Environmental Science and Pollution Research on November 2nd, 2021. See the published version at https://doi.org/10.1007/s11356-02117242-7. 
2 efficient surface-functionalized imogolite with nanoscale zero-

\section{valent iron material}

4 Estefanía M. Martinis ${ }^{\mathrm{a} *}$, Juliano C. Denardin ${ }^{\mathrm{b}}$, Raul Calderón ${ }^{\mathrm{c}, \mathrm{d}}$, Cristóbal Flores ${ }^{\mathrm{e}}$,

5 Karen Manquián-Cerda ${ }^{\mathrm{e}}$, Tamara Maldonado ${ }^{\mathrm{e}}$, Nicolás Arancibia-Miranda ${ }^{\mathrm{b}, \mathrm{e} *}$

6 a Facultad de Ingeniería, Universidad Nacional de Cuyo, Consejo Nacional de

7 Investigaciones Científicas y Técnicas, UNCUYO-CONICET, Mendoza, Argentina

$8{ }^{b}$ Center for the Development of Nanoscience and Nanotechnology, CEDENNA, Santiago,

$9 \quad$ Chile

$10 \quad{ }^{c}$ Centro de Investigación en Recursos Naturales y Sustentabilidad, Universidad Bernardo

11 O’Higgins, Fabrica, 1990, Segundo Piso, Santiago, Chile

$12{ }^{d}$ Instituto de Investigaciones Agropecuarias, INIA La Platina, Santa Rosa, 11610,

13 Santiago, Chile

$14{ }^{e}$ Facultad de Química y Biología, Universidad de Santiago de Chile, Santiago, Chile

15 *Corresponding authors. Tel.: +56 2 7181048; fax: +56 227181048

16 E-mail address: nicolas.arancibia@usach.cl (N. Arancibia-Miranda)

17 emartinis@mendoza-conicet.gob.ar (Estefanía M. Martinis) 
20 A novel hybrid nanomaterial, nanoscale zero-valent iron (nZVI)-grafted imogolite 21 nanotubes (Imo), was synthesized via a fast and straightforward chemical procedure. The 22 as-obtained nanomaterial (Imo-nZVI) was characterized using transmission electron 23 microscopy (TEM), electrophoretic mobility (EM) and vibrating sample magnetometry 24 (VSM). The prepared Imo-nZVI was superparamagnetic at room temperature and could 25 be easily separated by an external magnetic field. Sorption batch experiments were 26 performed in single- and multicomponent system and showed that $\mathrm{Hg}^{2+}$ and $\mathrm{Pb}^{2+}$ could 27 be quantitatively adsorbed at $\mathrm{pH} 4.0$ with maximum adsorption capacities of 62.3 and $2873.8 \mathrm{mg} \cdot \mathrm{g}^{-1}$, respectively. It was observed that the functional groups in Imo-nZVI interact 29 preferentially with analytes according to Misono Softness parameter. The higher 30 performance of Imo-nZVI compared with Imo and nZVI is related to the increased 31 adsorption sites in the functionalized nanomaterial. The sorption equilibrium data obeyed 32 the Langmuir model, while kinetic studies demonstrated that the sorption processes of $33 \mathrm{Hg}^{2+}$ and $\mathrm{Pb}^{2+}$ followed the pseudo-second-order model. This study suggests that the Imo34 nZVI composite can be used as a promising sorbent and provides a simple and fast 35 separation method for the removal of $\mathrm{Hg}$ and $\mathrm{Pb}$ ions from contaminated water.

36 Keywords: Imogolite; Nanoscale zero valent iron (nZVI); Hybrid material; Neurotoxic 37 metals $(\mathrm{Hg}$ and $\mathrm{Pb})$ removal 
Nanoscale zero-valent iron (nZVI) has recently emerged as powerful and versatile sorbents for potential use in environmental engineering. Because of their special physicochemical properties, such as a high surface-to-volume ratio, magnetism and in situ reactivity, nZVI materials have attracted substantial interest in the scientific community. nZVI has shown application in a wide array of environmental treatments, such as soil, sediment, and groundwater remediation (Crane \&Scott 2012, Li et al. 2006, Stefaniuk et al. 2016, Yan et al. 2010). However, nZVI forms aggregates due to van der Waals and magnetic forces, which decrease its efficiency by reducing its surface area and producing a less negative oxidation-reduction potential (Shi et al. 2011). Different approaches based on immobilization techniques have been developed for nZVI stabilization. Diatomite, zeolites, montmorillonite or cellulose have been used as matrices to increase the stability of nZVI (Arancibia-Miranda et al. 2016, Bossa et al. 2017, Dror et al. 2012, Kim et al. 2013, Suazo-Hernández et al. 2020, Suazo-Hernández et al. 2019, Zou et al. 2016). Furthermore, the sorption capacity of nZVI can also be improved by synergistically combining it with other nanomaterials. In this sense, inorganic nanotubes based on aluminosilicates, called imogolite (Imo), have attracted much research attention due to their one-dimensional structure, mechanical resistance and reactive surfaces (Arancibia-Miranda et al. 2020, Arancibia-Miranda et al. 2015). Imogolite is a hydrated

57 aluminosilicate with the chemical formula $(\mathrm{OH})_{3} \mathrm{Al}_{2} \mathrm{O}_{3} \mathrm{SiOH}$ (Cradwick et al. 1972). Characterized as a nanotubular structure, imogolite has a variable length from $100 \mathrm{~nm}$ to several microns, an internal diameter of $1 \mathrm{~nm}$, and an external diameter of $2 \mathrm{~nm}$ for natural

60 Imo, whereas synthetic Imo has a diameter in the range of 2.3-2.7 nm according to the 61 synthesis method (Arancibia-Miranda et al. 2013b). Imogolite is amphoteric because the inner surface of nanotubes is lined with isolated silanol $(\equiv \mathrm{SiOH})$ groups, and the outer 
surface of nanotubes is covered with both $\mathrm{Al}-\mathrm{O}-\mathrm{Al}$ and $\mathrm{Al}-\mathrm{OH}-\mathrm{Al}$ groups, determining the superficial properties of this material (Arancibia-Miranda et al. 2017). Because of its high dispersibility in water and the amphoteric character of Imo, which is strongly influenced by the $\mathrm{pH}$ of the medium (Arancibia-Miranda et al. 2015), cations should be able to interact with the inner surface and anions with the outer surface of the nanotubes (Bonelli 2016). Due to the special properties of imogolite, this nanomaterial has attracted substantial interest in the scientific community because of its potential application in the removal of cations and anions from polluted water (Arancibia-Miranda et al. 2020, Bonelli 2016, Levard et al. 2009).

In this work, we propose the functionalization of imogolite with nZVI as a strategy to obtain a powerful and new sorbent nanomaterial with magnetic properties. The combination of both nanomaterials can be synergistically used to enhance the extraction efficiency of certain analytes (Bonelli 2016). In this context, recent research has shown that the high reactivity of nZVI promotes the stabilization of potential contaminants through multiple processes, such as adsorption, reduction, oxidation, precipitation and coprecipitation (Jiang et al. 2018, Lu et al. 2016). However, it is important to consider that mechanisms of removal for nZVI are dependent on conditions of the media $(\mathrm{pH}$ and redox potential $\left.\left(\mathrm{E}_{\mathrm{h}}\right)\right)$, but also on the type, chemical status, and nature of the analyte. In this sense, the sorption preferences and specific interactions between the substrate and the analyte are dependent on (i) the hydrolysis constant of the metal ion (considering the presence of $\equiv \mathrm{X}-\mathrm{OH}$ and $\equiv \mathrm{X}-\mathrm{O}-\mathrm{OH}$ groups), (ii) polarizability, (iii) ionic and hydrated radius, and (iv) trend to form covalent bonds. In this context, Sposito (1989) postulated a relationship for an atom, defined as the Misono softness parameter, to form covalent bonds according to its ionic radius and ionization potential (Sposito 1989). A large

87 Misono softness value for an atom indicates its preference for electrostatic and inner- 
sphere surface complexation reactions. In this work, the removal of $\mathrm{Hg}$ and $\mathrm{Pb}$ from water samples was studied. $\mathrm{Hg}$ and $\mathrm{Pb}$ have long been a worrying issue due to their high neurotoxicity and widespread occurrence (Charlet et al. 2012, Jaishankar et al. 2014). The potential health risks from low levels of $\mathrm{Hg}$ and $\mathrm{Pb}$ are a subject of intense debate. Therefore, removal of these two metals from water samples is a current challenge. Taking these factors into consideration, along with the potential advantages resulting from the combination of imogolite and nZVI, synthesis and characterization of the hybrid nanomaterial and kinetic extraction studies of $\mathrm{Hg}^{2+}$ and $\mathrm{Pb}^{2+}$ are presented.

\section{Experimental}

\subsection{Instrumentation}

Elemental detection was performed using a PerkinElmer 5100ZL atomic absorption spectrometer (PerkinElmer, Norwalk, CT, USA) equipped with a pyrolytic graphite tube

100 and a transversely heated graphite atomizer Zeeman-effect background correction system

101 (PerkinElmer, Norwalk, CT, USA). $\mathrm{Hg}$ and $\mathrm{Pb}$ electrodeless discharge lamps (EDL) (PerkinElmer) operated at currents of $170 \mathrm{~mA}$ and $360 \mathrm{~mA}$ (modulated operation) and wavelengths of $253.7 \mathrm{~nm}$ and $283.3 \mathrm{~nm}$, respectively, with a spectral bandpass of $0.7 \mathrm{~nm}$,

104 were used. All measurements were made based on absorbance signals with an integration 105 time of $5 \mathrm{~s}$.

106 A centrifuge (model 5810, Eppendorf, Germany) was used to accelerate the phase

107 separation process. A reciprocating shaker (Boeco, Hamburg, Germany) was used to mix 108 the reagents. A Horiba F-51 pH meter (Kyoto, Japan) was used for $\mathrm{pH}$ determinations.

\subsection{Reagents}


110 All reagents were of analytical grade, and the presence of $\mathrm{Hg}$ was not detected within the

111 working range. A $1000 \mu \mathrm{g} \mathrm{mL}^{-1} \mathrm{Hg}^{2+}$ stock solution was prepared from mercury(II)

112 nitrate (Merck, Darmstadt, Germany) in 0.1 mol L $^{-1} \mathrm{HNO}_{3}$ (Ultrex ${ }^{\circledR}$ II Mallinckrodt

113 Baker, Phillipsburg, NJ, USA). Lower concentrations of $\mathrm{Hg}^{2+}$ were prepared by diluting

114 the stock solution with $0.1 \mathrm{~mol} \mathrm{~L}^{-1} \mathrm{HNO}_{3}$. A $1000 \mu \mathrm{g} \mathrm{mL} \mathrm{m}^{-1} \mathrm{~Pb}^{2+}$ stock solution was

115 prepared from lead(II) nitrate (Merck, Darmstadt, Germany) in 0.1 mol L-1 $\mathrm{HNO}_{3}$. Stock

116 solutions of $150 \mathrm{mg} \mathrm{L}^{-1} \mathrm{Mg}\left(\mathrm{NO}_{3}\right)_{2}$ (Merck) and $2500 \mathrm{mg} \mathrm{L}^{-1} \mathrm{NH}_{4} \mathrm{H}_{2} \mathrm{PO}_{4}$ (Merck) were

117 prepared and used as chemical modifiers. These solutions were prepared in $0.1 \%(\mathrm{v} / \mathrm{v})$

$118 \mathrm{HNO}_{3} \mathrm{~A} \mathrm{KNO}_{3}$ (Merck) solution $\left(2 \mathrm{~mol} \mathrm{~L}^{-1}\right)$ was used to adjust the ionic strength.

119 Ultrapure water $(18 \mathrm{M} \Omega \mathrm{cm})$ was obtained from a Millipore Continental Water System

120 (Bedford, MA, USA).

121 For the synthesis of Imo, the reagents used were tetraethyl orthosilicate $(99.995 \%$,

122 Sigma-Aldrich), $\mathrm{NaOH}\left(99.996 \%\right.$, Merck), and $\mathrm{Al}\left(\mathrm{NO}_{3}\right)_{2} \cdot 9 \mathrm{H}_{2} \mathrm{O}$ (99.998\%, Merck). The

123 coating procedure involved the use of $\mathrm{Fe}\left(\mathrm{NO}_{3}\right)_{3} \cdot 6 \mathrm{H}_{2} \mathrm{O}$ (99.998\%, Merck), $\mathrm{NaBH}_{4}$

124 (99.997\%, Sigma-Aldrich) and absolute ethanol (Merck). In sorption studies, $\mathrm{KNO}_{3}$

125 (99.998\%, Merck) was used. When needed, reagent grade solvents were considered.

126 Ultrapure water $(18 \mathrm{M} \Omega \mathrm{cm})$ was obtained from a Millipore Continental Water System

127 (Bedford, MA, USA). All reactions were conducted at ambient conditions.

\subsection{Synthesis of imogolite}

129 Imo was prepared according to the procedure described by Arancibia-Miranda et al.

130 (Arancibia-Miranda et al. 2011). 
132 nZVI was synthesized according to Arancibia-Miranda et al. procedure.[7] The new Imo-

133 nZVI was obtained as follow: the coating process had a theoretical 2:1 mixture of Imo/Fe

134 (w/w), obtained by dissolving $24.41 \mathrm{~g}$ of $\mathrm{Fe}\left(\mathrm{NO}_{3}\right)_{3} \cdot 6 \mathrm{H}_{2} \mathrm{O}$ in $100 \mathrm{~mL}$ of EtOH:H $\mathrm{H}_{2} \mathrm{O}$

135 (90:10) in a $500 \mathrm{~mL}$ round bottom flask. Then, Imo $(2.50 \mathrm{~g})$ suspended in $100 \mathrm{~mL}$ of

$136 \mathrm{EtOH}: \mathrm{H}_{2} \mathrm{O}(9: 1)$ was added. The suspension was stirred for $3 \mathrm{~h}$, leading to a lighter

137 orange-red solution. The $\mathrm{NaBH}_{4}$ reducing agent $(20.0 \mathrm{~g})$ dissolved in $100 \mathrm{~mL}$ of $\mathrm{H}_{2} \mathrm{O}$ was

138 immediately added at room temperature, causing the solution to turn black within 30-60

$139 \mathrm{~s}$, and the reaction mixture was stirred for approximately $1 \mathrm{~h}$ under a $\mathrm{N}_{2}$ atmosphere. The

140 product was collected in a Falcon tube and centrifuged. The supernatant was removed,

141 and the precipitated product was cleaned with an ethanol EtOH: $\mathrm{H}_{2} \mathrm{O}(9: 1)$ solution several

142 times. Finally, the product was frozen with liquid $\mathrm{N}_{2}$ and lyophilized.

\section{Characterization}

144 The products were characterized by X-ray diffraction (XRD), transmission electron

145 microscopy (TEM), electrophoretic mobility (EM) and vibrating sample magnetometry

146 (VSM). The samples were studied on a diffractometer (Shimadzu XRD-6000) at 1.5418

$147 \AA$ with $\mathrm{CuK} \alpha$ radiation in the $2 \theta$ region of $5-80^{\circ}$. A Zeiss EM 910 transmission electron

148 microscope using an $80 \mathrm{kV}$ acceleration potential on carbon substrates was prepared as

149 follows: A drop of the sample suspended in water was transferred onto the face of a

150 freshly cleaved sheet of mica, and the solvent was allowed to evaporate.

151 The magnetic response of the samples was investigated with a vibrating sample

152 magnetometer (VSM) operated at room temperature with a maximum magnetic field of

1531.2 Tesla and a sensitivity of $10^{-4} \mathrm{emu}$. The isoelectric point (IEP) was determined by

154 measuring the zeta potential of particles on a Zeta Meter ZM-4.0 apparatus.

155 Approximately $30 \mathrm{mg}$ of each sample was suspended in $200 \mathrm{~mL}$ of a solution with an 
156 ionic strength of $0.01 \mathrm{~mol} \cdot \mathrm{L}^{-1}\left(\mathrm{KNO}_{3}\right)$, and the EM was determined as a function of $\mathrm{pH}$.

157 The IEP was obtained from the EM versus $\mathrm{pH}$ graph as the $\mathrm{pH}$ at which $\mathrm{EM}=0$. The

158 specific surface areas (SSAs) of imogolite, nZVI and Imo-nZVI were measured by the

$159 \mathrm{~N}_{2}$ method of Brunauer-Emmett-Teller (BET), and pore size was calculated from Barrett,

160 Joyner and Halenda $(\mathrm{BJH})$ analysis of $\mathrm{N}_{2}$ adsorption/desorption isotherms at $77 \mathrm{~K}$ using

161 an automatic analyzer (Quantachrome Nova Station A, Quantachrome, USA, Florida).

\subsection{Sorption studies}

163 Batch adsorption of $\mathrm{Pb}^{2+}$ and $\mathrm{Hg}^{2+}$ was studied in $40 \mathrm{~mL}$ polypropylene centrifuge tubes 164 containing $10 \mathrm{mg}$ of imogolite and Imo-nZVI in $10 \mathrm{~mL}$ of a $\mathrm{Hg}^{2+} \mathrm{or} \mathrm{Pb}^{2+}$ solution in 0.01

$165 \mathrm{~mol} \cdot \mathrm{L}^{-1} \mathrm{KNO}_{3}$, respectively. The dependence of metal adsorption as a function of time 166 was studied in a solution of $\mathrm{Pb}$ or $\mathrm{Hg}$ containing $60 \mathrm{mg} \cdot \mathrm{L}^{-1}$ in equilibrium with $10 \mathrm{mg}$ of

167 imogolite and Imo-nZVI. The samples were equilibrated using a reciprocating shaker for $168300 \mathrm{~min}$. The temperature for the experiments was $298 \mathrm{~K}$, and the $\mathrm{pH}$ condition was 3.0 $169 \pm 0.2$ for both metals (see Table S1). The samples were centrifuged at 10,000 rpm for 10

$170 \mathrm{~min}$, and the supernatant was filtered through $0.22 \mathrm{~mm}$ Millex-GX membranes and 171 analyzed by ETAAS. The amount of adsorbed metals was determined from the difference 172 between the initial and final concentrations in solution, according to Eq. (1).

$173 q_{t}=\frac{\left(C_{o}-C_{t}\right) V}{M}$

174 where $C_{o}$ and $C_{t}$ are the initial metal concentrations in $\mathrm{mg} \cdot \mathrm{L}^{-1}$ and at time $\mathrm{t}$, respectively;

$175 \mathrm{~V}(\mathrm{~L})$ is the volume; and $\mathrm{M}(\mathrm{g})$ is the mass of the substrate.

\subsection{Sorption kinetics models}

Pseudo-first-order model (PFO)

178 In this model, the kinetic rate equation is given by: 
180 where $\mathrm{q}_{\mathrm{e}}$ and $\mathrm{q}_{\mathrm{t}}$ correspond to the amount adsorbed and in equilibrium at time $\mathrm{t}$, expressed

181 in $\mathrm{mg} \cdot \mathrm{g}^{-1}$, respectively, and $\mathrm{k}_{1}$ is the pseudo-first-order adsorption rate constant $\left(\mathrm{min}^{-1}\right)$,

182 which is a combination of the adsorption $\left(\mathrm{k}_{\mathrm{a}}\right)$ and desorption $\left(\mathrm{k}_{\mathrm{d}}\right)$ constants (Boparai et

183 al. 2011, Lagergren 2013, Manquián-Cerda et al. 2017, Rudzinski \&Panczyk 2000).

184 Integration of this equation from $\mathrm{t}=0$ to $\mathrm{t}=\mathrm{t}$ and $\mathrm{q}=0$ to $\mathrm{q}=\mathrm{q}$ gives

$$
\log \left(q_{e}-q_{t}\right)=\log \left(q_{e}\right)-\frac{k_{1}}{2.303} t(3)
$$

\section{Pseudo-second-order model (PSO)}

187 In this case, the driving force $\left(\mathrm{q}_{\mathrm{e}}-\mathrm{q}_{\mathrm{t}}\right)$ is proportional to the portion of activated sites

188 available on the sorbent (Ho \&McKay 2000, Rao et al. 2006, Rudzinski \&Plazinski 2008).

189 The kinetic rate equation follows the expression:

$190 \quad \frac{d q_{t}}{d t}=k_{2}\left(q_{e}-q_{t}\right)^{2}$

191 Rearranging the variables in this equation and integrating between times 0 and $\mathrm{t}$ and the

192 corresponding boundary conditions 0 and q gives:

$193 \quad \frac{t}{q_{t}}=\frac{1}{q_{e}^{2} k_{2}}+\frac{1}{q_{e}} t(5)$

194 The initial adsorption rate of the system can be estimated by this model and determined

195 by $\mathrm{h}=\mathrm{k} \cdot \mathrm{q}_{\mathrm{e}}^{2}$, obtained directly from the intercept of the curve.

196 Elovich equation

197 This model is used to describe the chemisorption processes on heterogeneous surfaces; it

198 considers that adsorption takes place in two stages: a fast reaction, mainly associated with

199 the movement of the adsorbate over outer active sites, and diffusion (slow) into and out

200 of the adsorbent pores (Arancibia-Miranda et al. 2020, Arancibia-Miranda et al. 2015,

201 Chien \&Clayton 1980, Wu et al. 2001, 2009). This model is expressed as: 
$202 \frac{d q_{t}}{d t}=\alpha \exp \left(-\beta q_{t}\right)(6)$

203 The constant $\alpha\left(\mathrm{mg} \cdot \mathrm{g}^{-1} \cdot \mathrm{min}^{-1}\right)$ is regarded as the initial rate, and parameter $\beta\left(\mathrm{g} \cdot \mathrm{mg}^{-1}\right)$ is

204 an indication of the number of sites available for adsorption, which is related to the extent

205 of surface coverage and activation energy for chemisorption. Given that $\mathrm{q}_{\mathrm{t}}=0$ at $\mathrm{t}=0$,

206 the integrated form is:

$207 \quad q_{t}=\left(\frac{1}{\beta}\right) \ln (\alpha \beta)+\frac{1}{\beta} \ln t(7)$

208 Parameters $\alpha$ and $\beta$ are obtained from the slope and intercept of the $\mathrm{q}_{\mathrm{t}} \mathrm{vs} . \ln \mathrm{t}$ plot,

209 respectively.

210 Intraparticle diffusion model (Weber-Morris model)

211 Webber-Morris's pore-diffusion model is a single-resistance model derived from Fick's

212 second law of diffusion (Cáceres-Jensen et al. 2013, Cheung et al. 2007, Weber \&Morris

213 1963). If the sorption process is considered to be influenced by diffusion in the sorbent

214 and by convective diffusion in the sorbate solution, then the mathematical dependence of

215 sorbate uptake, $\mathrm{q}_{\mathrm{t}}$, at $\mathrm{t}^{1 / 2}$ is given by the equation:

$216 \quad q_{t}=k_{\mathrm{int}} t^{1 / 2}+C$

217 where $k_{\text {int }}\left(\mathrm{mg} \cdot \mathrm{g}^{-1} \cdot \mathrm{min}^{-1 / 2}\right)$ is the intraparticle diffusion constant and $\mathrm{C}$ is a constant related

218 to the thickness of the surface layer; the higher the value of $\mathrm{C}$ obtained from the $\mathrm{q}_{\mathrm{t}} v s . \mathrm{t}^{1 / 2}$

219 plot, the greater the boundary layer effect, which is related to intraparticle diffusivity.

220 Langmuir Isotherm

221 This model assumes that the analyte is adsorbed in a determined number of active sites,

222 forming a monolayer. The Langmuir equation is described by

$223 q_{e}=\frac{q_{m} K_{L} C_{e}}{1+K_{L} C_{e}}(9)$ 
224 where $\mathrm{q}_{\mathrm{m}}\left(\mathrm{mg} \cdot \mathrm{g}^{-1}\right)$ is the maximum adsorption capacity, $\mathrm{q}_{\mathrm{e}}\left(\mathrm{mg} \mathrm{g}^{-1}\right)$ is the amount of

225 analyte adsorbed, $\mathrm{K}_{\mathrm{L}}$ is the Langmuir constant and $\mathrm{C}_{\mathrm{e}}$ is the equilibrium molar

226 concentration of the analyte $\left(\mathrm{mg} \cdot \mathrm{L}^{-1}\right)$.

\section{Results and discussion}

\subsection{Characterization of the composite}

The samples were analyzed by X-ray diffraction to evaluate the changes generated from the coating process of imogolite with nZVI and $\mathrm{Hg}$ and $\mathrm{Pb}$ removal in single and multicomponent systems (Fig. S1). For imogolite, four broad peaks were identified at 21.0, 12.0, 3.4, and $2.2 \AA$, corresponding to the (hkl) (100), (110), (001), and (211) planes, respectively. According to previous reports, these planes are associated with monoclinic or hexagonal packaging (Arancibia-Miranda et al. 2013a, Kang et al. 2014). In the case of nZVI, diffraction peaks at $2 \theta=45.0^{\circ}$ (corresponding to the 110 plane) and $2 \theta=65.5^{\circ}$ (corresponding to the 200 plane) were observed, which also correspond to elemental Fe (Arancibia-Miranda et al. 2016, Kanel et al. 2005, Zhang et al. 2011). Fe oxide diffraction peaks were determined in nZVI, corresponding to magnetite and maghemite. The diffractogram of composite Imo-nZVI showed bands attributed to imogolite and nZVI, with clear differences in the degree of crystallinity of the peak in comparison to the starting materials. No signs of Fe oxides were observed in the composite, suggesting that nZVI oxidation did not occur or that the percentage of Fe oxide was less than the detection capacity of the XRD equipment. The process of $\mathrm{Hg}$ and $\mathrm{Pb}$ removal in single and multicomponent systems caused significant changes in the degree of crystallinity of the composites, altering the structure of the immobilized nZVIs in imogolite. After the removal process (single and multicomponent), the corrosion products magnetite $\left(\mathrm{Fe}_{3} \mathrm{O}_{4}\right)$

247 and lepidocrocite $(\gamma-\mathrm{FeOOH})($ Baltazar et al. 2014, Kanel et al. 2005) were identified 
248 (Fig. S1). Both species are byproducts of the energetically favorable redox reactions

249 between the nZVI and the analytes, as is described in equations 10 and 11 .

$$
n Z V I+P b^{2+} \rightarrow F e^{2+}+P b^{o} \quad\left(E^{o}=0.32 V\right)
$$

$$
n Z V I+H g^{2+} \rightarrow F^{2+}+H g^{o} \quad\left(E^{o}=1.30 V\right)
$$

However, according to the significant differences in the standard redox potential for $\mathrm{Pb}^{2+} / \mathrm{Pb}^{0}(-0.12 \mathrm{~V})$ and $\mathrm{Hg}(\mathrm{II}) / \mathrm{Hg}(0)(0.86 \mathrm{~V})$ couples with respect to the $\mathrm{Fe}^{0} / \mathrm{Fe}^{(\mathrm{II})}(-0.44$

V) couple, the removal of $\mathrm{Hg}^{2+}$ occurs preferentially by a reductive precipitation at the nZVI surface (Lagergren 2013), whereas that removal process of $\mathrm{Pb}^{2+}$ occurs by sorption with partial chemical reduction (Noubactep 2008).

It is important to highlight that in the multicomponent system, the samples have a lower degree of crystallinity, which shows that the presence of both metals significantly alters 260 the surface of nZVI.

261 The morphologies of the samples were obtained through a detailed microscopic analysis

262 (Fig. 1). The dimensions of imogolite were determined by images retrieved by HR-TEM.

263 The external diameter was approximately $2 \mathrm{~nm}$, with a length that exceeded $500 \mathrm{~nm}$. For nZVI, two clearly defined areas were observed. The first area presented a higher degree of crystallinity located in the nucleus, corresponding to metallic Fe, while on the external surface, there was a second amorphous area associated with iron oxides, a process widely described in the literature. The coating process of imogolite with nZVI showed a heterogeneous distribution, in which areas with a high presence of agglomerated nZVI are highlighted. This is due to the synthesis conditions of nZVI, where the acid character

270 of Fe (Lewis acid) favors positive charges at superficial sites of imogolite, decreasing the 271 adsorption of this cation, which occurs at sites of greater specificity, a phenomenon 
272 similar to that reported by Arancibia-Miranda et al., 2014. The dimensions of nZVI were

273 also sensitive to the process of its immobilization in imogolite, and the size was $20 \%$

274 lower than that of nZVI synthesized without support.

275 The surface behavior of the study materials was described through measurements of zeta

276 potential (ZP) (Fig. 2), a technique that is sensitive to the changes that a surface can suffer

277 in its composition. The isoelectric point is considered an indicative parameter of what 278 occurs on the surface of imogolite due to being coated with nZVI. Imogolite has a pH-

279 sensitive surface charge and is positive over a wide $\mathrm{pH}$ range with an IEP value of 10.5,

280 which favors anion adsorption (Arancibia-Miranda et al. 2011). On the other hand, this

281 parameter of nZVI reached a value of 7.7, which is characteristic of this type of material.

282 The coating process with nZVI caused a drastic change in the IEP value of Imo-nZVI, 283 which presented a value of 8.3 , in addition to a decrease in the magnitude of the generated

284 surface charge. The decrease in the IEP value observed in the composite reduces the 285 potential electrostatic impediments in the processes of divalent ion sorption, as occurs in 286 imogolite. The textural properties of the samples (Table 1) show that as a result of coating, 287 the SSA and pore volume decrease while the pore diameter increases.

288 The hysteresis curve of presorption Imo-nZVI shows a typical ferromagnetic curve with 289 a saturation magnetization $\left(\mathrm{M}_{\mathrm{s}}\right)$ of $16.5 \mathrm{emu} \cdot \mathrm{g}^{-1}$ and a coercive field $\left(\mathrm{H}_{\mathrm{c}}\right)$ of $100 \mathrm{Oe}($ Fig. 290 S2). The $\mathrm{Pb}$ postsorption magnetization curve presents a decrease in $M s$ to $7 \mathrm{emu} \cdot \mathrm{g}^{-1}$. 291 This decrease in magnetization is attributed to the amount of $\mathrm{Pb}$ that has been absorbed 292 by the Imo-nZVI nanoparticles, which does not contribute to the magnetization of the sample. A much larger decrease in $M_{s}$ is observed for the postsorption samples with $\mathrm{Hg}$ and $\mathrm{Pb}-\mathrm{Hg}$, with values of $0.6 \mathrm{emu} \cdot \mathrm{g}^{-1}$ and $0.56 \mathrm{emu} \cdot \mathrm{g}^{-1}$, respectively. The coercivity of 295 the postsorption samples remains close to 100 Oe in all samples. This perturbation on the 
magnetic properties of the materials under study could be related to the different corrosion

297 products from nZVI, which has less magnetic character than $\mathrm{Fe}^{0}$.

\subsection{Adsorption kinetics}

299 The effect of the contact time on the removal of $\mathrm{Hg}^{2+}$ and $\mathrm{Pb}^{2+}$ in single and

300 multicomponent systems was evaluated for the different materials by means of removal

301 kinetics. In the case of imogolite, an equilibrium time was achieved at 60 minutes for both

302 single- and multicomponent systems. For nZVI and Imo-nZVI, equilibrium was reached

303 after 30 minutes in all the studied systems (Fig. 3). $\mathrm{Pb}^{2+}$ removal was slightly higher than

$304 \mathrm{Hg}^{2+}$ removal in all the systems under study.

\subsection{PFO and PSO models}

306 Kinetic models of pseudo first order (PFO) and pseudo-second order (PSO) (Fig. 4) were

307 used to describe the kinetic behavior of the experimental data. The PFO model showed

308 the least adjustment of these data (Table 2). This behavior could be explained by the

309 theoretical fundamentals that differentiate both models. For example, in the case of the

310 PFO model, high levels of adjustment are observed when the analyte is monovalent,

311 which is removed by direct interaction between this species and a surface active site of

312 the substrate. For the PSO model, this condition occurs when an ion is attracted at two

313 active sites in the substrate. The removal of divalent cations is explained by this model,

314 favoring a chemical-type interaction (chemisorption), probably forming bidentate

315 complexes (Table 2).

316 The sorption capacities $\left(\mathrm{q}_{\mathrm{e}}\right)$ of imogolite obtained from the PSO model (Eq. 5) for $\mathrm{Pb}^{2+}$

317 and $\mathrm{Hg}^{2+}$ were 44.9 and $39.4 \mathrm{mg} \cdot \mathrm{g}^{-1}$, respectively, in single-component systems.

318 However, as a result of the competition between cations, a reduction of more than $10 \%$ 
319 was observed in the sorption capacity of imogolite in multicomponent systems. In the

320 case of nZVI, the removal of these metals was higher in both systems under study. This

321 is because this nanoparticle has multiple mechanisms of removal (adsorption, 322 precipitation, coprecipitation, and oxidation-reduction), unlike imogolite, for which

323 adsorption is the only mode of removal. The functionalization of imogolite with nZVI

324 improved the removal capacity of both $\mathrm{Hg}^{2+}$ and $\mathrm{Pb}^{2+}$ compared to the starting materials,

325 where the $\mathrm{q}_{\mathrm{e}}$ values in the case of $\mathrm{Pb}^{2+}$ in single and multicomponent systems were 78.0 326 and $72.4 \mathrm{mg} \cdot \mathrm{g}^{-1}$ and 81.0 and $77.7 \mathrm{mg} \cdot \mathrm{g}^{-1}$, for $\mathrm{Hg}^{2+}$, respectively. The removal rates of

327 both metals obtained from the PSO model (Eq. 5) show that the functionalization process

328 generates an increase in this parameter, which is up to 2.3 times greater than that observed

329 for imogolite and nZVI. The initial velocity (h), calculated from the PSO model, showed

330 that $\mathrm{Pb}^{2+}$ is removed by Imo-nZVI in early sorption stages compared to $\mathrm{Hg}^{2+}$.

\subsection{Adsorption mechanisms}

332 The sorption mechanisms of $\mathrm{Hg}$ and $\mathrm{Pb}$ analytes in imogolite, nZVI and Imo-nZVI were analyzed using the Elovich equation and Weber-Morris models (Fig. 5).

\section{Elovich equation}

335 The Elovich equation (Eq. 7) is a widely used model in various systems whose reactive

336 sites are energetically heterogeneous. The $\alpha$ parameter, associated with the initial rate of

337 adsorption, was higher in single-component systems for all the substrates studied,

338 indicating that the presence of both cations $\left(\mathrm{Hg}^{2+}\right.$ and $\left.\mathrm{Pb}^{2+}\right)$ generated a strong 339 competition for the active sites available in each material, explaining the lower values of

$340 \alpha$ in multicomponent systems (Table 3). The desorption constant obtained from this model $(\beta)$ was lower in the single-component systems, indicating that the different 
342 available active sites can remove metals, observing the following decreasing order for

343 both metals Imo-nZVI> nZVI> imogolite (Fig. 5). However, in competition, this

344 parameter increases, showing that the removal of these analytes occurs in sites of greater

345 specificity.

\section{Intraparticle diffusion kinetic model}

347 As previously discussed (Table 3), the immobilization of nZVI in imogolite generated 348 changes in textural properties, which could generate changes in the overall removal rate 349 of $\mathrm{Hg}^{2+}$ and $\mathrm{Pb}^{2+}$. The data were adjusted using the Weber-Morris model (Eq. 8) to 350 determine these changes and whether intraparticle diffusion is the limiting step of the 351 global speed for the removal process (Table 3). In general, multilinearity was observed

352 for all the systems under study. Reductive precipitation and surface sorption are the main 353 removal mechanism, with percentages greater than $90 \%\left(\mathrm{q}_{\mathrm{e}-1}\right.$ values $)$ of the analytes in all 354 the systems evaluated (Fig. 5), which is consequence of new sites of adsorption (Fe-OH and $\mathrm{Fe}-\mathrm{O}-\mathrm{OH}$ ) that provides the surface-functionalized imogolite with nZVI. C is related to the thickness of the limiting layer associated with instantaneous adsorption. This parameter was lower in multicomponent systems, which implies that accessibility to the active sites where sorption occurs is dependent on the composition of the solution,

359 showing higher values for $\mathrm{Hg}$. This result could be associated with the chemical

360 characteristics of this element (i.e., ionic radius, polarizability, and electronegativity).

\section{Isotherm sorption}

362 The isotherms were studied for all elements in the single and multicomponent systems

363 (Fig. 6, Table 4) at $\mathrm{pH} 4.0$, considering a range of concentrations of $\mathrm{Hg}^{2+}$ and $\mathrm{Pb}^{2+}$

364 between 1 and $50 \mathrm{mg} \cdot \mathrm{L}^{-1}$. In general, the curves of the isotherms showed an "L"-type 365 shape, which indicates good affinity between the substrate and the analytes, as well as a 
greater removal capacity in the single-component systems. However, in nZVI and the nanocomposite, the removal was greater than that in imogolite because in both substrates, the interactions are favored due to the displacement of the IEP and decrease in ZP. The experimental data were adjusted using the Langmuir model (Eq. 9), where $\mathrm{q}_{\max }$ corresponds to the maximum removal capacity $\left(\mathrm{mg} \cdot \mathrm{g}^{-1}\right)$ and $\mathrm{K}_{\mathrm{L}}$ is the Langmuir constant associated with the removal capacity $\left(\mathrm{L} \cdot \mathrm{mg}^{-1}\right)$.

372 All the materials in the single and multicomponent systems showed higher values of $\mathrm{q}_{\max }$ and $\mathrm{K}_{\mathrm{L}}$ for $\mathrm{Pb}^{2+}$ than for $\mathrm{Hg}^{2+}$. The values of $\mathrm{q}_{\max }$ for $\mathrm{Pb}^{2+}$ and $\mathrm{Hg}^{2+}$ in the single and multicomponent systems had the same descending sequence: Imo-nZVI>nZVI >> Imogolite. Regarding the adsorption intensity $\left(\mathrm{K}_{\mathrm{L}}\right)$, the nanocomposite showed an increase in this parameter, reaching 1.2 and 1.4 times higher values in comparison to nZVI and imogolite, respectively, probably associated with the decrease in the size of nZVI immobilized on the surface of imogolite (Table 4).

According to Misono softness parameters ( $\mathrm{Y}_{\mathrm{Hg} 2+}=4.24$ y $\mathrm{Y}_{\mathrm{Pb} 2+}=3.58$ ) (Misono et al. 1967), the functional groups of nZVI favored a stronger interaction with $\mathrm{Hg}^{2+}$ than $\mathrm{Pb}^{2+}$, due to the fact that Fe has a borderline character on the Misono softness scale. This observation is in agreement with the $\mathrm{K}_{\mathrm{L}}$ value, which is a measure of the metal ion affinity to the adsorption sites on materials, which is enhanced in multicomponent systems (Table 4). The free energy $\left(\Delta G^{\circ}\right)$ was determined for each material in the systems under study at a temperature of $25{ }^{\circ} \mathrm{C}$ and $\mathrm{pH}=4.0$ through the following equation: $\Delta \mathrm{G}^{\circ}=-\mathrm{RT} \ln \mathrm{K}$, where $\mathrm{R}$ is the gas constant $\left(8.134 \mathrm{~J} \mathrm{~mol}^{-1} \cdot \mathrm{K}^{-1}\right)$ and $\mathrm{T}$ the temperature $(\mathrm{K})$ using the

387 Langmuir isotherms (Table S1). However, Zhou \& Zhou (2014) reported that $\mathrm{K}_{\mathrm{L}}$ cannot be used directly to obtain this parameter because it is expressed as $\mathrm{L} \cdot \mathrm{mg}^{-1}$. The standard equilibrium constant $\left(\mathrm{K}^{\circ}\right)$ using the Langmuir equation was calculated to avoid this

390 problem using the equation $\mathrm{K}^{\circ}=\mathrm{K}_{\mathrm{L}} \cdot 10^{3} \cdot 55.5$ and replaced in the Gibbs free energy 
equation. The data obtained from this equation determined negative values of $\Delta \mathrm{G}^{\circ}$ for the

392 removal of $\mathrm{Pb}^{2+}$ and $\mathrm{Hg}^{2+}$ for imogolite, nZVI and the nanocomposite, both for single and multicomponent systems (Table $\mathrm{S} 1$ ). Hence, the process of removing $\mathrm{Pb}^{2+}$ and $\mathrm{Hg}^{2+}$ is spontaneous and thermodynamically favorable.

395 Role of imogolite as a support for $\mathbf{n Z V I}$ and its effects on the removal of $\mathbf{P b}^{\mathbf{2 +}}$ and $396 \mathbf{H g}^{2+}$.

397 The structural and surface characteristics of imogolite describe how this nanotubular 398 aluminosilicate significantly favors the removal of neurotoxic metals, such as $\mathrm{Pb}^{2+}$ and $399 \mathrm{Hg}^{2+}$, in single and multicomponent systems when it is used as a support for nZVI. Several 400 investigations have shown that in situ synthesis of nZVI in different substrates, such as activated carbon, zeolite, kaolinite, and montmorillonite, causes a decrease in size and increase the removal capacity of nZVI; however, the impact of this process in imogolite has important nuances to take into account:

404 Due to the variable charge of imogolite, which is positive with ZP values higher than 25 $405 \mathrm{mV}$ between $\mathrm{pH} 3$ and 7, the formation of nZVI occurs mainly at the edges of the nanotube, indicating that the surface sites have higher sensitivity to changes in $\mathrm{pH}$, which are neutral or negatively charged according to the synthesis conditions of nZVI, favoring the adsorption of $\mathrm{Fe}^{3+}$ and generating nuclei of attraction for other iron ions.

409 The high density and magnetic and hydrophilic properties of nZVI prevent it from being 410 suspended, leading to rapid agglomeration and oxidation in aqueous systems, reducing 411 the removal capacity of different analytes (Peng et al. 2018). In contrast, the behavior of 412 imogolite is opposite to that described for nZVI since it remains in a stable suspension, 413 even under conditions of unfavorable $\mathrm{pH}$ and ionic strength, due to its low density and 
414 because water can structure itself in different ways in the pores of imogolite, which allows

415 the Imo-nZVI composite to be in suspension under conditions when nZVI is not.

416 Immobilization of nZVI on imogolite increases the reactivity of the material adding a new

417 type of surface active sites with functional groups such as $\equiv \mathrm{Fe}^{(\mathrm{II})}-\mathrm{OH}$, $\equiv \mathrm{Fe}^{(\mathrm{II})}-\mathrm{OOH}$,

$418 \equiv \mathrm{Fe}^{(\mathrm{III})}-\mathrm{OH}$, and $\equiv \mathrm{Fe}^{(\mathrm{III})}-\mathrm{OOH}$, generated through the oxidation of the nZVI. These

419 functional groups could preferentially react with $\mathrm{Hg}^{2+}$ or $\mathrm{Pb}^{2+}$ according to the softness

420 of the analytes and the polarizability of the $\mathrm{Fe}(\mathrm{II}) / \mathrm{Fe}(\mathrm{III})$ group. Thus, hard $\mathrm{Pb}^{2+}$ would

421 interact preferentially with more polarized $\equiv \mathrm{Fe}^{(\mathrm{III})}-\mathrm{OOH}$ and $\equiv \mathrm{Fe}^{(\mathrm{III})}-\mathrm{OH}$ groups whereas

422 softer $\mathrm{Hg}^{2+}$ would interact with $\equiv \mathrm{Fe}^{(\mathrm{II})}-\mathrm{OH}$ and $\equiv \mathrm{Fe}^{(\mathrm{II})}-\mathrm{OOH}$ groups (Fig. 7).

\section{Conclusions}

424 The hybrid nanomaterial (Imo-nZVI) synthesized in this work represents a very interesting type of material because of its exceptional properties and potential use in a wide range of application fields. The synergistic combination of both components was efficiently tested as a sorbent material for neurotoxic metals removal. Based on the speeds and removal capacities obtained, $\mathrm{Pb}^{2+}$ was preferably removed by all materials, even in systems that coexisted with $\mathrm{Hg}^{2+}$. The process of immobilizing nZVI in imogolite caused an increase of the speed and removal capacity of both metals compared to the starting materials because the nZVI present in the nanocomposite is smaller than free nZVI. The PSO and Langmuir models showed a better adjustment of the experimental data for all

433 the cases under study, which suggests that the removal process is produced by 434 chemisorption. The free energy associated with the removal of $\mathrm{Pb}^{2+}$ and $\mathrm{Hg}^{2+}$ indicates that this process is spontaneous in all materials and is more favorable in nZVI. The excellent percentage of recovery for $\mathrm{Pb}^{2+}$ and $\mathrm{Hg}^{2+}$ from water matrices and the magnetic properties of Imo-nZVI make it a promising material for environmental applications. 


\section{Declarations}

440 Ethics approval and consent to participate

$441 \quad$ Not applicable

442 Consent for publication

$443 \quad$ Not applicable

444 Availability of data and materials

$445 \quad$ Not applicable

446 Competing interests

447 The authors declare that they have no competing interests

$448 \quad$ Funding

449 This work was supported by Consejo Nacional de Investigaciones Científicas y Técnicas

450 (CONICET), Agencia Nacional de Promoción Científica y Tecnológica (FONCYT)

451 (PICT-BID), Universidad Nacional de Cuyo (Argentina), Financiamiento Basal para

452 Centros Científicos y Tecnológicos de Excelencia AFB180001, Fondecyt Regular

453 1191018, PAI 77190014 and REDES 170170. CONICYT-PFCHA/Doctorado

454 Nacional/2019-21191242. ANID/CONICYT Postdoctoral FONDECYT N 3180488

455 Authors' contributions

456 All authors contributed to the study conception and design. Material preparation, data

457 collection and analysis were performed by Estefanía M. Martinis and Nicolás Arancibia-

458 Miranda. Material characterization and sorption kinetic data analysis were performed

459 by Juliano C. Denardin, Raul Calderón, Cristóbal Flores, Karen Manquián-Cerdae and

460 Tamara Maldonadoe. The first draft of the manuscript was written by Estefania M.

461 Martinis and Nicolás Arancibia-Miranda. and all authors commented on previous

462 versions of the manuscript. All authors read and approved the final manuscript.

463 Acknowledgements 
464 Consejo Nacional de Investigaciones Científicas y Técnicas (CONICET), Agencia 465 Nacional de Promoción Científica y Tecnológica (FONCYT) (PICT-BID), Universidad 466 Nacional de Cuyo (Argentina), Financiamiento Basal para Centros Científicos y 467 Tecnológicos de Excelencia AFB180001, Fondecyt Regular 1191018, PAI 77190014 and 468 REDES 170170. C.F. acknowledges CONICYT-PFCHA/Doctorado Nacional/2019469 21191242. T.M. acknowledges ANID/CONICYT Postdoctoral FONDECYT N 3180488. 470 
Arancibia-Miranda N, Escudey M, Molina M, García-González MT (2011): Use of isoelectric point and $\mathrm{pH}$ to evaluate the synthesis of a nanotubular aluminosilicate. J. Non-Cryst. Solids 357, 1750-1756, https://doi.org/10.1016/j.jnoncrysol.2011.01.012

Arancibia-Miranda N, Escudey M, Molina M, García-González MT (2013a): Kinetic and surface study of single-walled aluminosilicate nanotubes and their precursors. Nanomaterials 3, 126-140, https://doi.org/10.3390/nano3010126

Arancibia-Miranda N, Lillo S, Escudey M (2013b): Nanotubular aluminosilicates: a case study for science and industry. J. Chil. Chem. Soc. 58, 2061-2066, https://doi.org/10.4067/S0717-97072013000400035

Arancibia-Miranda N, Silva-Yumi J, Escudey M (2015): Effect of cations in the background electrolyte on the adsorption kinetics of copper and cadmium and the isoelectric point of imogolite. J. Hazard. Mater. 299, 675-684, https://doi.org/10.1016/j.jhazmat.2015.08.007

Arancibia-Miranda N, Baltazar SE, García A, Muñoz-Lira D, Sepúlveda P, Rubio MA, Altbir D (2016): Nanoscale zero valent supported by Zeolite and Montmorillonite: Template effect of the removal of lead ion from an aqueous solution. J. Hazard. Mater. 301, 371-380, https://doi.org/10.1016/j.jhazmat.2015.09.007

Arancibia-Miranda N, Manquián-Cerda K, Pizarro C, Maldonado T, Suazo-Hernández J, Escudey M, Bolan N, Sarkar B (2020): Mechanistic insights into simultaneous removal of copper, cadmium and arsenic from water by iron oxide-functionalized magnetic imogolite nanocomposites. J. Hazard. Mater. 398, 122940, https://doi.org/10.1016/j.jhazmat.2020.122940

Arancibia-Miranda Ns, Escudey M, Ramírez R, González RI, Van Duin AC, Kiwi M (2017): Advancements in the synthesis of building block materials: experimental evidence and modeled interpretations of the effect of $\mathrm{Na}$ and $\mathrm{K}$ on imogolite synthesis. J. Phys. Chem. B 121, 12658-12668, https://doi.org/10.1021/acs.jpcc.6b12155

Baltazar SE, García A, Romero AH, Rubio MA, Arancibia-Miranda N, Altbir D (2014): Surface rearrangement of nanoscale zerovalent iron: the role of $\mathrm{pH}$ and its implications in the kinetics of arsenate sorption. Environ. Technol. 35, 2365-2372, https://doi.org/10.1080/09593330.2014.904932

Bonelli B (2016): Surface chemical modifications of imogolite, Developments in Clay Science. Elsevier, pp. 279-307

Boparai HK, Joseph M, O'Carroll DM (2011): Kinetics and thermodynamics of cadmium ion removal by adsorption onto nano zerovalent iron particles. J. Hazard. Mater. 186, 458-465, https://doi.org/10.1016/j.jhazmat.2010.11.029

Bossa N, Carpenter AW, Kumar N, de Lannoy C-F, Wiesner M (2017): Cellulose nanocrystal zero-valent iron nanocomposites for groundwater remediation. Environ. Sci. Nano 4, 1294-1303, https://doi.org/10.1039/C6EN00572A

Cáceres-Jensen L, Rodríguez-Becerra J, Parra-Rivero J, Escudey M, Barrientos L, Castro-Castillo V (2013): Sorption kinetics of diuron on volcanic ash derived soils. J. Hazard. Mater. 261, 602-613, https://doi.org/10.1016/j.jhazmat.2013.07.073

Cradwick P, Farmer V, Russell J, Masson C, Wada K, Yoshinaga N (1972): Imogolite, a hydrated aluminium silicate of tubular structure. Nat. Phys. Sci. 240, 187-189, https://doi.org/10.1038/physci240187a0 
Crane R, Scott T (2012): Nanoscale zero-valent iron: future prospects for an emerging water treatment technology. J. Hazard. Mater. 211, 112-125, https://doi.org/10.1016/j.jhazmat.2011.11.073

Charlet L, Chapron Y, Faller P, Kirsch R, Stone AT, Baveye PC (2012): Neurodegenerative diseases and exposure to the environmental metals $\mathrm{Mn}, \mathrm{Pb}$, and Hg. Coord. Chem. Rev. 256, 2147-2163, https://doi.org/10.1016/j.ccr.2012.05.012

Cheung W, Szeto Y, McKay G (2007): Intraparticle diffusion processes during acid dye adsorption onto chitosan. Bioresour. Technol. 98, 2897-2904, https://doi.org/10.1016/j.biortech.2006.09.045

Chien S, Clayton W (1980): Application of Elovich equation to the kinetics of phosphate release and sorption in soils. Soil Sci. Soc. Am. J. 44, 265-268, https://doi.org/10.2136/sssaj1980.03615995004400020013x

Dror I, Jacov OM, Cortis A, Berkowitz B (2012): Catalytic transformation of persistent contaminants using a new composite material based on nanosized zero-valent iron. ACS Appl. Mater. Inter. 4, 3416-3423, https://doi.org/10.1021/am300402q

Ho Y-S, McKay G (2000): The kinetics of sorption of divalent metal ions onto sphagnum moss peat. Water Res. 34, 735-742, https://doi.org/10.1016/S00431354(99)00232-8

Jaishankar M, Tseten T, Anbalagan N, Mathew BB, Beeregowda KN (2014): Toxicity, mechanism and health effects of some heavy metals. Interdiscip. Toxicol. 7, 6072, https://doi.org/10.2478/intox-2014-0009

Jiang D, Zeng G, Huang D, Chen M, Zhang C, Huang C, Wan J (2018): Remediation of contaminated soils by enhanced nanoscale zero valent iron. Environ. Res. 163, 217-227, https://doi.org/10.1016/j.envres.2018.01.030

Kanel SR, Manning B, Charlet L, Choi H (2005): Removal of arsenic (III) from groundwater by nanoscale zero-valent iron. Environ. Sci. Technol. 39, 1291-1298, https://doi.org/10.1021/es048991u

Kang D-Y, Brunelli NA, Yucelen GI, Venkatasubramanian A, Zang J, Leisen J, Hesketh PJ, Jones CW, Nair S (2014): Direct synthesis of single-walled aminoaluminosilicate nanotubes with enhanced molecular adsorption selectivity. Nat. Commun. 5, 1-9, https://doi.org/10.1038/ncomms4342

Kim SA, Kamala-Kannan S, Lee K-J, Park Y-J, Shea PJ, Lee W-H, Kim H-M, Oh B-T (2013): Removal of $\mathrm{Pb}$ (II) from aqueous solution by a zeolite-nanoscale zerovalent iron composite. Chem. Eng. J. 217, 54-60, https://doi.org/10.1016/j.cej.2012.11.097

Lagergren S (2013): Zur theorie der sogenannten adsorption gelöster stoffe, KungligaSvenska Vetenskapsakademiens. Handlingar 24: 1-39

Levard C, Doelsch E, Rose J, Masion A, Basile-Doelsch I, Proux O, Hazemann J-L, Borschneck D, Bottero J-Y (2009): Role of natural nanoparticles on the speciation of Ni in andosols of la Reunion. Geochim. Cosmochim. Acta 73, 4750-4760, https://doi.org/10.1016/j.gca.2009.05.053

Li X-q, Elliott DW, Zhang W-x (2006): Zero-valent iron nanoparticles for abatement of environmental pollutants: materials and engineering aspects. Crit. Rev. Solid State Mater. Sci. 31, 111-122, https://doi.org/10.1080/10408430601057611

Lu HJ, Wang JK, Ferguson S, Wang T, Bao Y, Hao HX (2016): Mechanism, synthesis and modification of nano zerovalent iron in water treatment. Nanoscale 8, 99629975, https://doi.org/10.1039/c6nr00740f

Manquián-Cerda K, Cruces E, Rubio MA, Reyes C, Arancibia-Miranda N (2017): Preparation of nanoscale iron (oxide, oxyhydroxides and zero-valent) particles 
derived from blueberries: reactivity, characterization and removal mechanism of arsenate. Ecotox. Environ. Safe. 145, 69-77, https://doi.org/10.1016/j.ecoenv.2017.07.004

Misono M, Ochiai Ei, Saito Y, Yoneda Y (1967): A new dual parameter scale for the strength of Lewis acids and bases with the evaluation of their softness. J. Inorg. Nucl. Chem. 29, 2685-2691, https://doi.org/10.1016/0022-1902(67)80006-X

Noubactep C (2008): A critical review on the process of contaminant removal in $\mathrm{Fe}^{\circ}-$ $\mathrm{H}_{2} \mathrm{O}$ systems. $\quad$ Environ. Technol. 29, 909-920, https://doi.org/10.1080/09593330802131602

Peng Z, Xiong C, Wang W, Tan F, Wang X, Qiao X, Wong PK (2018): Hydrophobic modification of nanoscale zero-valent iron with excellent stability and floatability for efficient removal of floating oil on water. Chemosphere 201, 110-118, https://doi.org/j.chemosphere.2018.02.149

Rao CNR, Müller A, Cheetham AK (2006): The chemistry of nanomaterials: synthesis, properties and applications. John Wiley \& Sons

Rudzinski W, Panczyk T (2000): Kinetics of isothermal adsorption on energetically heterogeneous solid surfaces: a new theoretical description based on the statistical rate theory of interfacial transport. J. Phys. Chem. B 104, 9149-9162, https://doi.org/10.1021/jp000045m

Rudzinski W, Plazinski W (2008): Kinetics of solute adsorption at solid/aqueous interfaces: searching for the theoretical background of the modified pseudo-firstorder kinetic equation. Langmuir 24, 5393-5399, https://doi.org/10.1021/la8000448

Shi Z, Nurmi JT, Tratnyek PG (2011): Effects of nano zero-valent iron on oxidationreduction potential. Environ. Sci. Technol. 45, 1586-1592, https://doi.org/10.1021/es103185t

Sposito G (1989): Chemistry of Soils. New York: Oxford University Pres. Inc, pp. 277

Stefaniuk M, Oleszczuk P, Ok YS (2016): Review on nano zerovalent iron (nZVI): from synthesis to environmental applications. Chem. Eng. J. 287, 618-632, https://doi.org/10.1016/j.cej.2015.11.046

Suazo-Hernández J, Sepúlveda P, Manquián-Cerda K, Ramírez-Tagle R, Rubio MA, Bolan N, Sarkar B, Arancibia-Miranda N (2019): Synthesis and characterization of zeolite-based composites functionalized with nanoscale zero-valent iron for removing arsenic in the presence of selenium from water. J. Hazard. Mater. 373, 810-819, https://doi.org/10.1016/j.jhazmat.2019.03.125

Suazo-Hernández J, Manquián-Cerda K, de la Luz Mora M, Molina-Roco M, Rubio MA, Sarkar B, Bolan N, Arancibia-Miranda N (2020): Efficient and selective removal of $\mathrm{SeVI}$ and $\mathrm{AsV}$ mixed contaminants from aqueous media by montmorillonitenanoscale zero valent iron nanocomposite. J. Hazard. Mater. 403, 123639, https://doi.org/10.1016/j.jhazmat.2020.123639

Weber WJ, Morris JC (1963): Kinetics of adsorption on carbon from solution. J. Sanit. Eng. Div. 89, 31-60, https://doi.org/10.1061/JSEDAI.0000430

Wu F-C, Tseng R-L, Juang R-S (2001): Kinetic modeling of liquid-phase adsorption of reactive dyes and metal ions on chitosan. Water Res. 35, 613-618, https://doi.org/10.1016/S0043-1354(00)00307-9

Wu F-C, Tseng R-L, Juang R-S (2009): Characteristics of Elovich equation used for the analysis of adsorption kinetics in dye-chitosan systems. Chem. Eng. J. 150, 366373, https://doi.org/10.1016/j.cej.2009.01.014 
616 Yan W, Herzing AA, Kiely CJ, Zhang W-x (2010): Nanoscale zero-valent iron (nZVI): 617 aspects of the core-shell structure and reactions with inorganic species in water. J. 618 Contam. Hydrol. 118, 96-104, https://doi.org/10.1016/j.jconhyd.2010.09.003

619 Zhang X, Lin S, Chen Z, Megharaj M, Naidu R (2011): Kaolinite-supported nanoscale 620

621

622

623 zero-valent iron for removal of $\mathrm{Pb} 2+$ from aqueous solution: reactivity, characterization and mechanism. Water Res. 45, 3481-3488, https://doi.org/10.1016/j.watres.2011.04.010

Zou Y, Wang X, Khan A, Wang P, Liu Y, Alsaedi A, Hayat T, Wang X (2016): Environmental remediation and application of nanoscale zero-valent iron and its composites for the removal of heavy metal ions: a review. Environ. Sci. Technol.

627 50, 7290-7304, https://doi.org/10.1021/acs.est.6b01897 
629 Fig. 1. Morphology of the samples obtained by HR-TEM.

630 Fig. 2. ZP vs. pH plot of synthetic Imo, nZVI, and Imo-nZVI.

631 Fig. 3. Effect of contact time on the removal of heavy metals from each sample.

632 Fig. 4. Kinetic models of pseudo first-order (PFO) for (a) Imo, (b) nZVI, and (c) Imo-

633 nZVI and pseudo second-order (PSO) for (d) Imo, (e) nZVI, and (f) Imo-nZVI.

634 Fig. 5. Fits of the experimental data to the Elovich equation for (a) imogolite, (b) nZVI,

635 and (c) Imo-nZVI and Weber-Morris model for (d) Imo, (e) nZVI, and (f) Imo-nZVI.

636 Fig. 6. Langmuir isotherm for the adsorption of $\mathrm{Pb}^{2+}$ and $\mathrm{Hg}^{2+}$ in single $(\mathrm{S})$ and

637 multicomponent (M) systems on nZVI, Imo, and Imo-nZVI.

638 Fig. 7. Schematic representation of the possible interactions that occur on the surface of 639 the Imo-nZVI. The affinity and intensity of removal of $\mathrm{Pb}^{2+}$ and $\mathrm{Hg}^{2+}$ with the different 640 groups of the nanocomposite is conditioned by the magnitude of the Misono softness 641 parameters $\left(\mathrm{YHg}^{2+}=4.24\right.$ and $\left.\mathrm{YPb}^{2+}=3.58\right)$ and the possibility they have of interacting 642 with functional groups with similar characteristics.

643

644

645

646 
$648 \quad$ Fig. 1

649

650

651

652

653

654

655

656

657

658

659

660

661

662

663

664

665

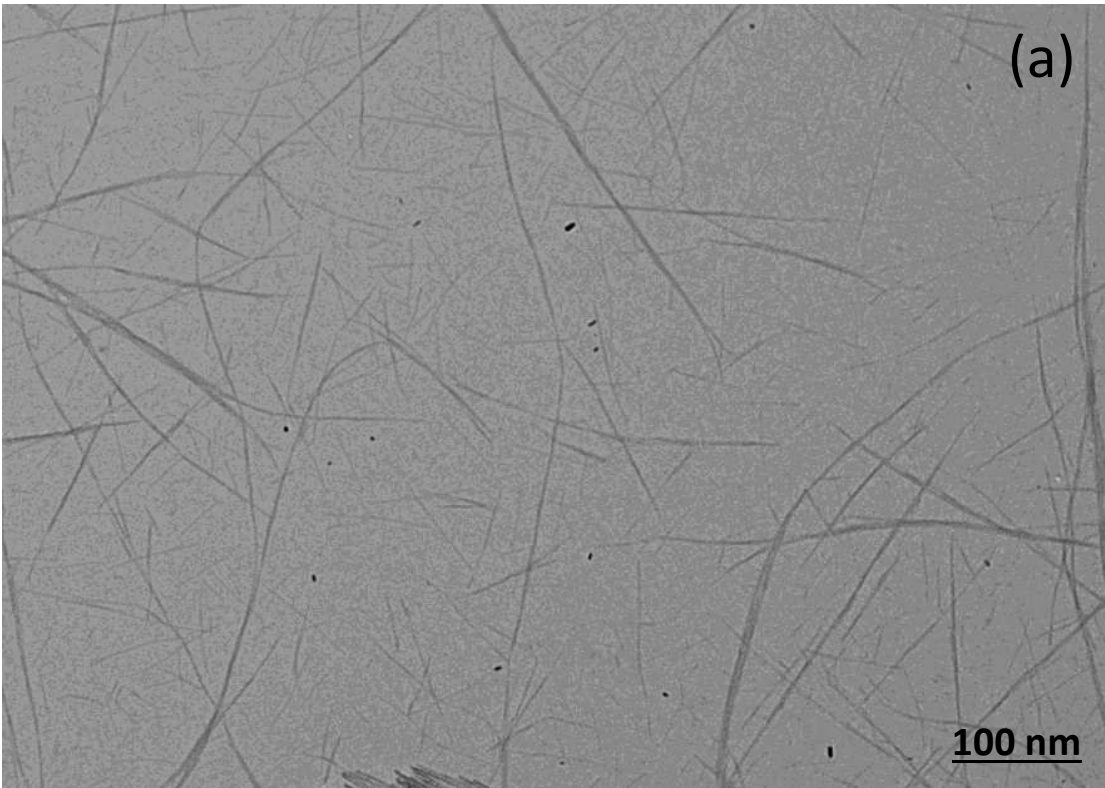

(a)

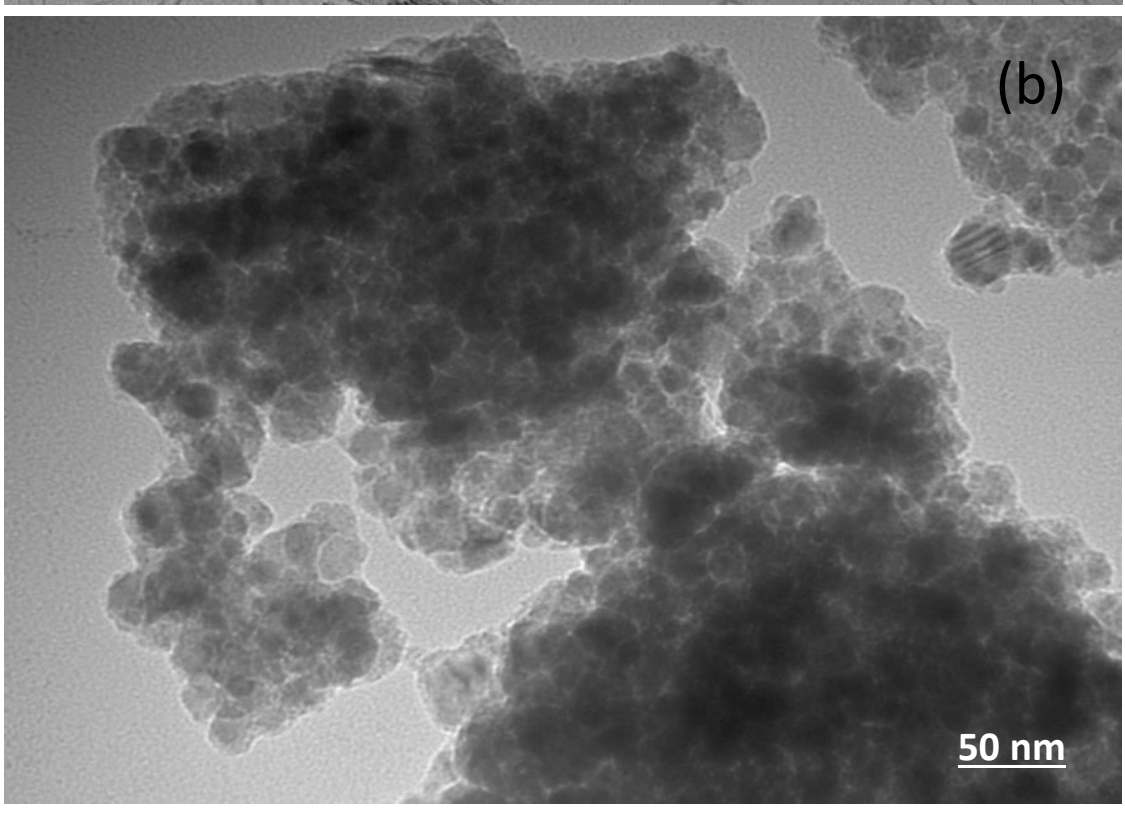

666

(c)

667

668

669

670

671

672

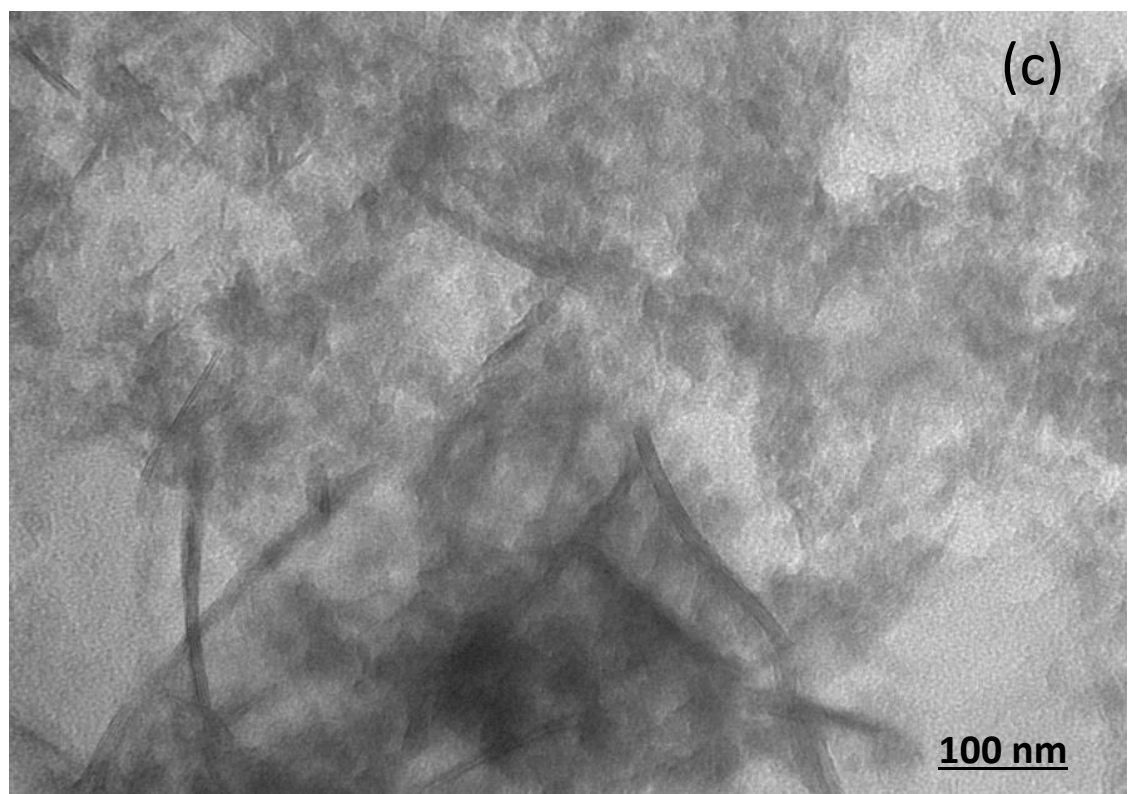


673 Fig. 2

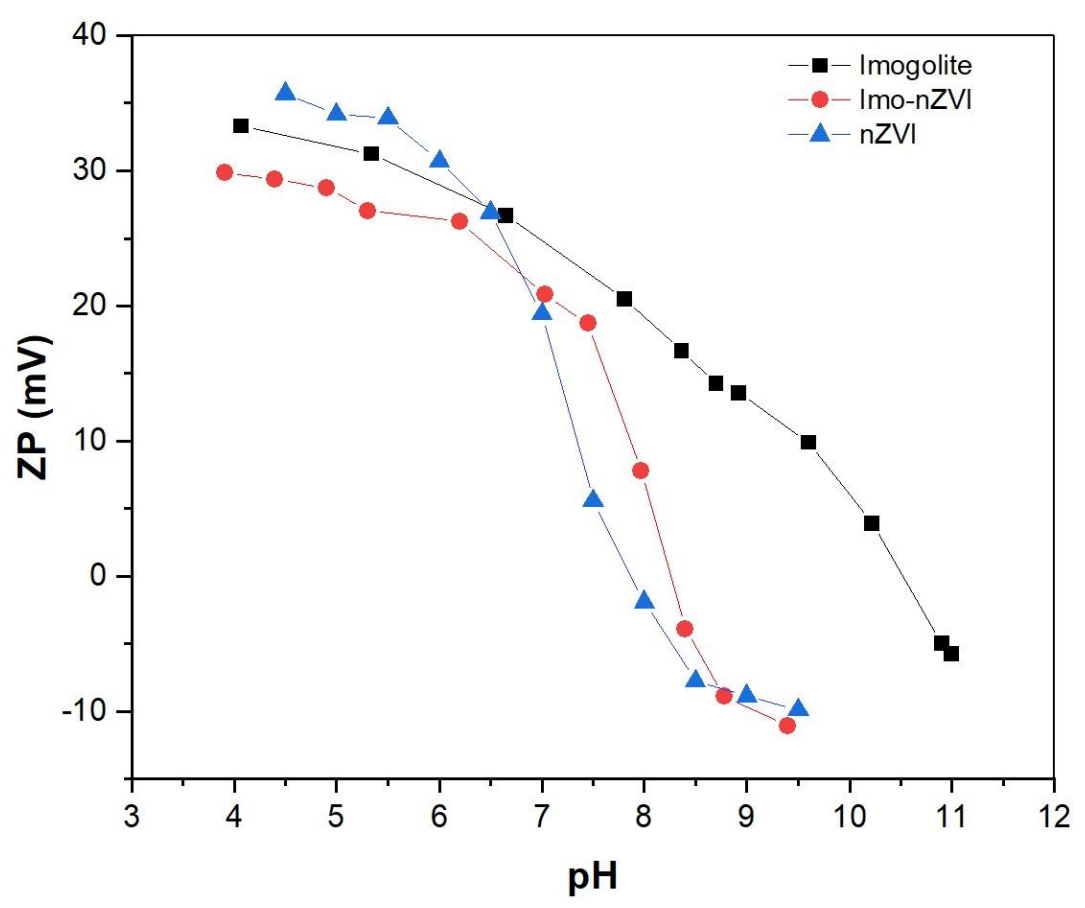

675

676

677

678

679

680

681

682

683

684 
Fig. 3

686
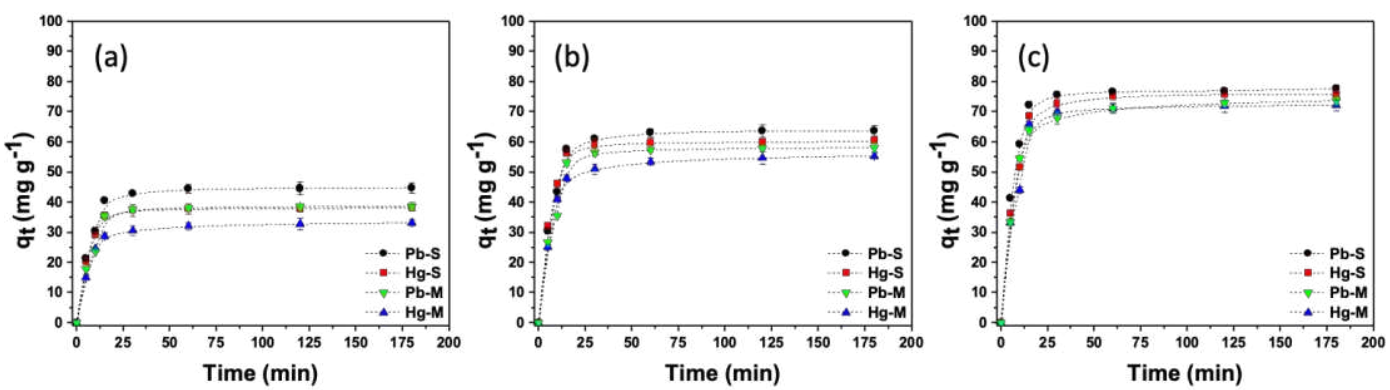

687

688

689

690

691

692

693

694

695

696

697

698

699

700

701

702

703

704

705 
Fig. 4
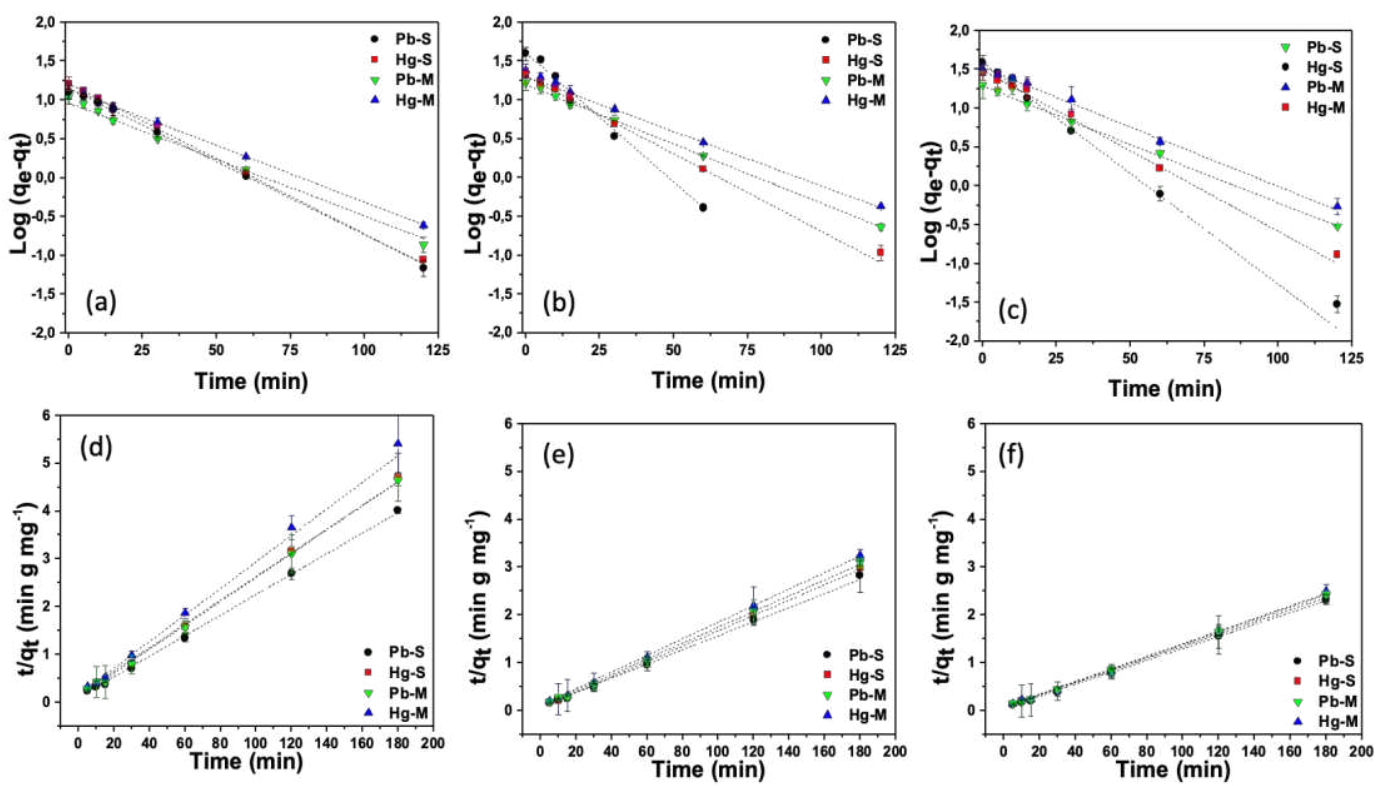

707

708

709

710

711

712

713

714

715

716

717

718

719

720

721

722 
Fig. 5
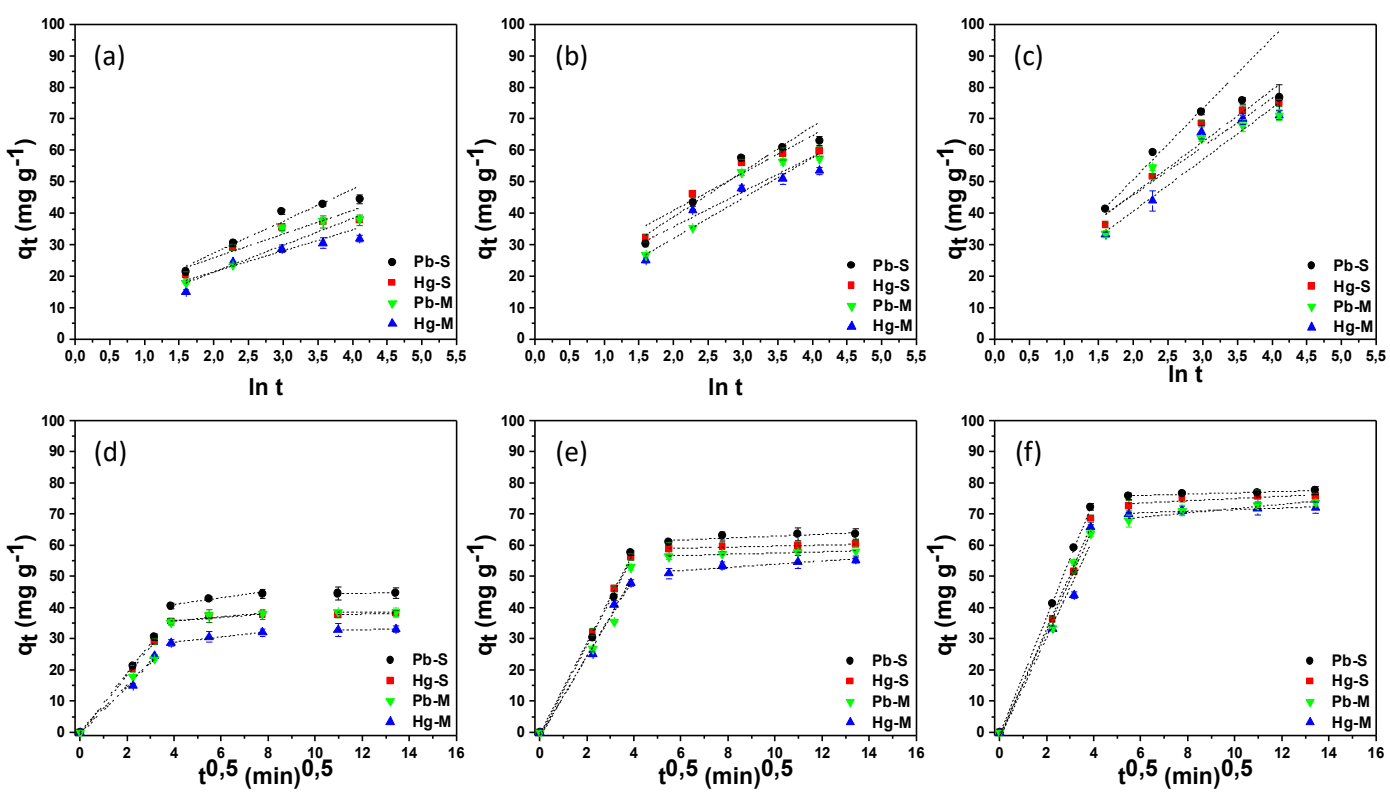

725

726

727

728

729

730

731

732

733 
Fig. 6

737
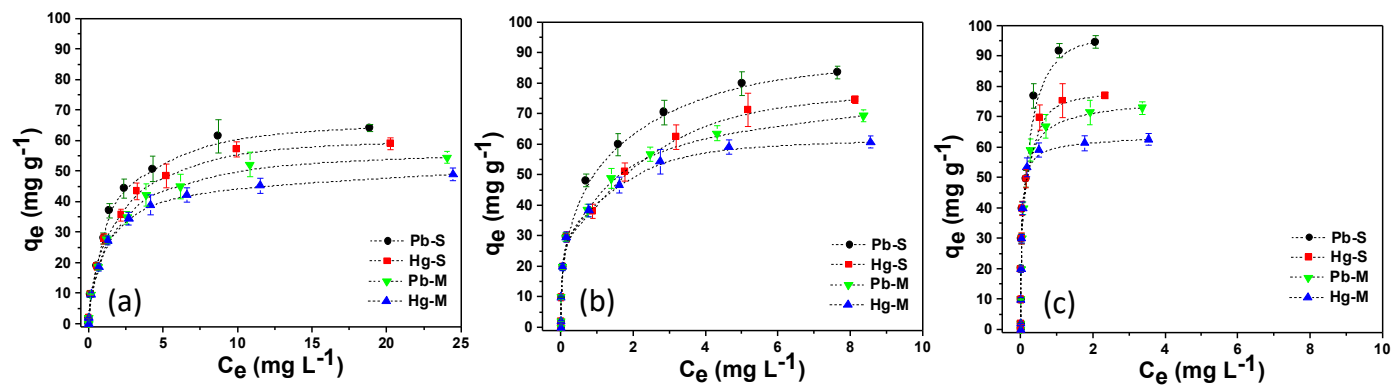

738

739

740

741

742

743

744

745

746

747

748

749

750

751

752

753

754

755

756 
Fig. 7

758

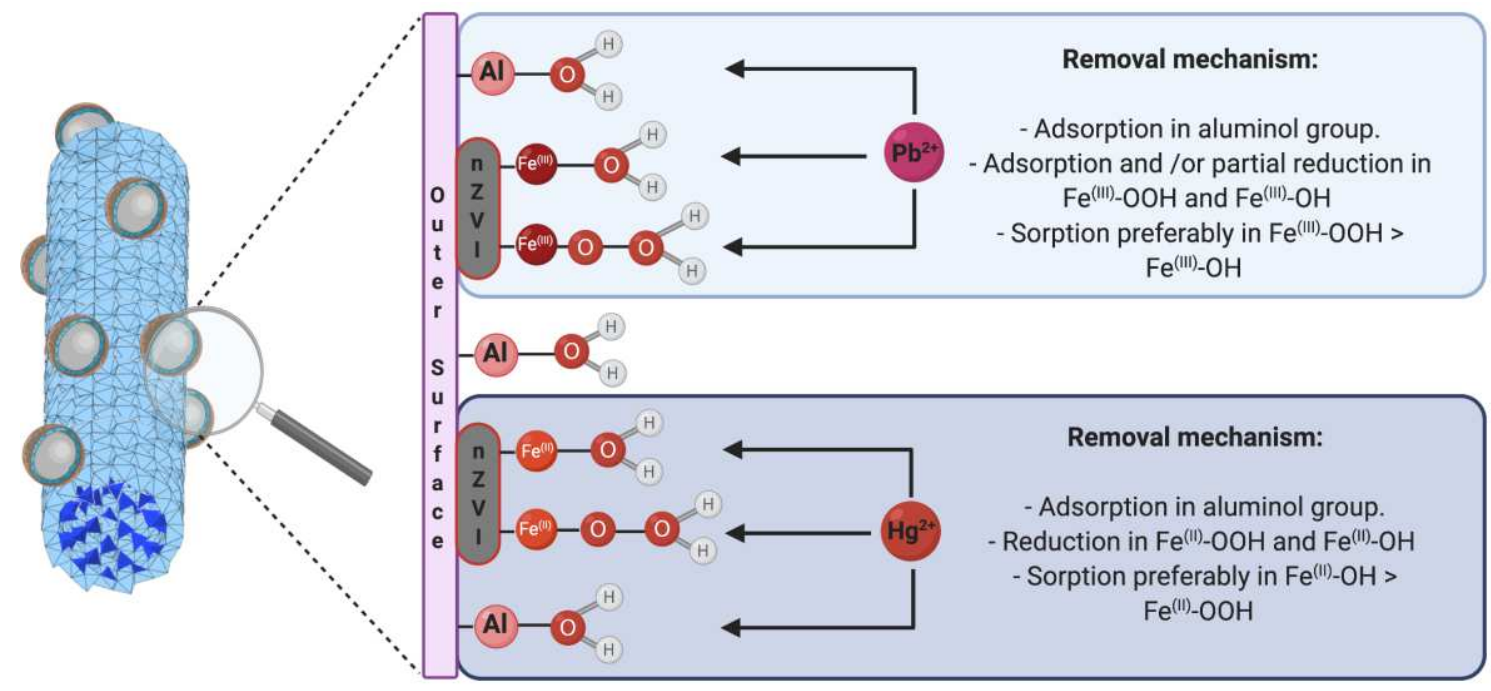

759

760

761

762

763

764

765

766

767

768

769

770

771

772

773

774

775 
776 Table 1. Specific surface area and porosity parameters of imogolite, nZVI and Imo-nZVI.

\begin{tabular}{cccc}
\hline Parameters & Imogolite & nZVI & Imo-nZVI \\
\hline $\begin{array}{c}\text { Specific surface area } \\
\left(\mathrm{m}^{2} \cdot \mathrm{g}^{-1}\right)\end{array}$ & 310 & 87 & 234 \\
$\begin{array}{c}\text { External surface area } \\
\left(\mathrm{m}^{2} \cdot \mathrm{g}^{-1}\right)\end{array}$ & 180 & 35 & 133 \\
$\begin{array}{c}\text { Micropore volume } \times 10^{-3} \\
\left(\mathrm{~cm}^{3} \cdot \mathrm{g}^{-1}\right)\end{array}$ & 20 & 1.5 & 26 \\
$\begin{array}{c}\text { Micropore area } \\
\left(\mathrm{m}^{2} \cdot \mathrm{g}^{-1}\right)\end{array}$ & 66 & 17 & 50 \\
$\quad \begin{array}{c}\text { Pore Volume } \\
\left(\mathrm{cm}^{3} \cdot \mathrm{g}-1\right)\end{array}$ & 0.25 & 0.18 & 0.22 \\
Pore diameter $(\AA)$ & 10 & 18 & 13 \\
\hline
\end{tabular}

777

778

779

780

781

782

783

784

785

786

787

788

789

790

791 
792 Table 2. Kinetic parameters predicted from pseudo first and pseudo second-order

793 models. Standard error for each parameter is included in parenthesis.

\begin{tabular}{|c|c|c|c|c|c|c|}
\hline \multirow{2}{*}{ Parameters } & \multicolumn{3}{|c|}{$\mathrm{Pb}^{2+}$ (single component) } & \multicolumn{3}{|c|}{$\mathrm{Pb}^{2+}$ (multi component) } \\
\hline & Imogolite & nZVI & Imo-nZVI & Imogolite & nZVI & Imo-nZVI \\
\hline$q \exp \left(m g \cdot g^{-1}\right)$ & $44.84(3.26)$ & $63.66(6.12)$ & $77.67(6.89)$ & $38.75(3.42)$ & $58.14(5.55)$ & $73.70(6.99)$ \\
\hline$q_{\exp }(\%)$ & $49.82(3.33)$ & $70.73(7.16)$ & $86.30(7.99)$ & $43.06(4.29)$ & $64.60(6.07)$ & $81.89(8.16)$ \\
\hline \multicolumn{7}{|c|}{ Pseudo-second Order } \\
\hline$q_{e}\left(m g \cdot g^{-1}\right)$ & $47.90(3.46)$ & $68.01(6.66)$ & $81.96(7.74)$ & $41.68(4.09)$ & $62.54(5.99)$ & $77.43(7.99)$ \\
\hline $\mathrm{k}_{2} \times 10^{-3}\left(\mathrm{~g} \cdot \mathrm{mg}^{-1} \cdot \mathrm{min}^{-1}\right)$ & $4.24(0.26)$ & $2.98(0.12)$ & $3.01(0.41)$ & $4.34(0.29)$ & $2.90(0.11)$ & $2.68(0.31)$ \\
\hline $\mathbf{h}\left(\mathbf{m g} \cdot \mathrm{g}^{-1} \cdot \mathbf{m i n}^{-1}\right)$ & 9.73 & 13.78 & 20.22 & 7.54 & 11.34 & 16.07 \\
\hline $\mathbf{r}^{2}$ & 0.972 & 0.977 & 0.987 & 0.969 & 0.983 & 0.977 \\
\hline \multirow{2}{*}{ Models } & \multicolumn{3}{|c|}{$\mathrm{Hg}^{2+}($ single component $)$} & \multicolumn{3}{|c|}{$\mathbf{H g}^{2+}($ multi component $)$} \\
\hline & Imogolite & nZVI & Imo-nZVI & Imogolite & nZVI & Imo-nZVI \\
\hline$q_{\exp }\left(\mathrm{mg} \cdot \mathrm{g}^{-1}\right)$ & $38.25(3.44)$ & $60.41(7.11)$ & $75.83(6.95)$ & $33.24(3.81)$ & $55.41(5.26)$ & $72.20(8.01)$ \\
\hline$q \exp (\%)$ & $42.50(3.98)$ & $67.12(6.14)$ & $84.26(7.33)$ & $36.93(3.06)$ & $61.57(5.17)$ & $80.22(7.94)$ \\
\hline \multicolumn{7}{|c|}{ Pseudo-second Order } \\
\hline $\mathrm{q}_{\mathrm{e}}\left(\mathbf{m g} \cdot \mathrm{g}^{-1}\right)$ & $40.36(4.46)$ & $63.74(6.53)$ & $81.01(8.03)$ & $34.92(3.80)$ & $58.21(5.11)$ & $77.66(7.26)$ \\
\hline $\mathrm{k}_{2} \times 10^{-3}\left(\mathrm{~g} \cdot \mathrm{mg}^{-1} \cdot \mathrm{min}^{-1}\right)$ & $6.54(0.51)$ & $4.14(0.46)$ & $2.50(0.22)$ & $5.95(0.61)$ & $3.57(0.41)$ & $2.33(0.29)$ \\
\hline $\mathbf{h}\left(\mathbf{m g} \cdot \mathbf{g}^{-1} \cdot \mathbf{m i n}^{-1}\right)$ & 10.65 & 16.82 & 16.41 & 7.26 & 12.10 & 14.05 \\
\hline $\mathbf{r}^{2}$ & 0.978 & 0.987 & 0.981 & 0.979 & 0.963 & 0.977 \\
\hline
\end{tabular}

794

795

796

797 
799 Table 3. Kinetic parameters predicted from the linear analysis of Elovich and intraparticle

800 diffusion kinetic models. Standard error for each parameter is included in parenthesis.

\begin{tabular}{|c|c|c|c|c|c|c|}
\hline \multirow{2}{*}{$\begin{array}{c}\text { Elovich } \\
\text { Equation }\end{array}$} & \multicolumn{3}{|c|}{$\mathbf{P b}^{2+}$ (single-component) } & \multicolumn{3}{|c|}{$\mathbf{P b}^{2+}$ (multi-component) } \\
\hline & Imogolite & nZVI & Imo-nZVI & Imogolite & nZVI & Imo-nZVI \\
\hline$\alpha$ & $9.09(0.51)$ & $16.39(2.01)$ & $18.94(1.71)$ & $8.50(1.10)$ & $11.54(0.83)$ & $11.99(1.21)$ \\
\hline$\beta$ & $0.06(0.00)$ & $0.07(0.01)$ & $0.07(0.00)$ & $0.06(0.01)$ & $0.07(0.00)$ & $0.10(0.01)$ \\
\hline RMSE & 0.41 & 5.75 & 0.51 & 18.00 & 1.03 & 11.58 \\
\hline $\mathbf{r}^{2}$ & 0.993 & 0.937 & 0.990 & 0.773 & 0.993 & 0.937 \\
\hline Elovich & \multicolumn{3}{|c|}{$\mathrm{Hg}^{2+}$ (single-component) } & \multicolumn{3}{|c|}{$\mathrm{Hg}^{2+}$ (multi-component) } \\
\hline Equation & Imogolite & nZVI & Imo-nZVI & Imogolite & nZVI & Imo-nZVI \\
\hline \multirow[t]{2}{*}{$\alpha$} & $16.94(1.24)$ & $18.84(2.31)$ & $24.35(2.63)$ & $13.64(0.11)$ & $14.17(2.03)$ & $19.52(0.19)$ \\
\hline & $0.05(0.00)$ & $0.05(0.01)$ & $0.06(0.00)$ & $0.09(0.00)$ & $0.10(0.02)$ & $0.14(0.00)$ \\
\hline RMSE & 1.41 & 40.51 & 16.43 & 1.70 & 62.46 & 2.49 \\
\hline $\mathbf{r}^{2}$ & 0.990 & 0.773 & 0.937 & 0.993 & 0.773 & 0.990 \\
\hline $\begin{array}{c}\text { Intraparticles } \\
\text { Diffusion }\end{array}$ & \multicolumn{3}{|c|}{$\mathbf{P b}^{2+}$ (single-component $)$} & \multicolumn{3}{|c|}{$\mathbf{P b}^{2+}$ (multi-component) } \\
\hline & Imogolite & nZVI & Imo-nZVI & Imogolite & nZVI & Imo-nZVI \\
\hline $\mathbf{q}_{\mathrm{e} 1}$ & $28.84(3.23)$ & $48.18(3.99)$ & $66.47(7.99)$ & $36.30(4.01)$ & $58.84(5.29)$ & $69.00(7.03)$ \\
\hline kint $_{1}$ & $0.10(0.02)$ & $0.16(0.02)$ & $0.36(0.05)$ & $0.31(0.02)$ & $0.52(0.04)$ & $0.25(0.03)$ \\
\hline $\mathbf{C}_{1}$ & $13.3(1.20)$ & $25.4(1.99)$ & $33.1(4.29)$ & $20.21(2.54)$ & $33.03(3.54)$ & $35.1(3.43)$ \\
\hline $\mathbf{r}^{2}$ & 0.951 & 0.951 & 0.857 & 0.950 & 0.950 & 0.954 \\
\hline Intraparticles & \multicolumn{3}{|c|}{$\mathrm{Hg}^{2+}$ (single-component) } & \multicolumn{3}{|c|}{$\mathrm{Hg}^{2+}$ (multi-component) } \\
\hline Diffusion & Imogolite & nZVI & Imo-nZVI & Imogolite & nZVI & Imo-nZVI \\
\hline qe1 & $34.29(4.01)$ & $52.00(5.78)$ & $74.82(7.09)$ & $41.04(4.21)$ & $58.57(5.99)$ & $73.96(8.01)$ \\
\hline kint $_{1}$ & $0.21(0.01)$ & $0.31(0.04)$ & $0.21(0.01)$ & $0.14(0.05)$ & $0.20(0.01)$ & $0.69(0.01)$ \\
\hline $\mathbf{C}_{1}$ & $17.35(2.23)$ & $27.15(2.27)$ & $72.7(5.99)$ & $22.3(3.01)$ & $31.1(3.02)$ & $41.3(4.12)$ \\
\hline $\mathbf{r}^{2}$ & 0.859 & 0.856 & 0.951 & 0.864 & 0.954 & 0.950 \\
\hline
\end{tabular}

801

802

803

804 
805 Table 4. Parameters of Langmuir isotherm models for $\mathrm{Pb}^{2+}$ and $\mathrm{Hg}^{2+}$ adsorption on

806 imogolite, nZVI and Imo-nZVI in single and multi-component systems. Standard error

807 for each parameter is included in parenthesis.

\begin{tabular}{|c|c|c|c|c|c|c|}
\hline \multirow{2}{*}{ Parameters } & \multicolumn{3}{|c|}{$\mathbf{P b}^{2+}$ (single-component $)$} & \multicolumn{3}{|c|}{$\mathrm{Pb}^{2+}$ (multi-component) } \\
\hline & Imogolite & nZVI & Imo-nZVI & Imogolite & nZVI & Imo-nZVI \\
\hline qmax & $68.84(7.22)$ & $81.43(8.31)$ & $94.77(9.42)$ & $62.75(7.01)$ & $70.65(7.07)$ & $76.94(7.13)$ \\
\hline $\mathbf{K}_{\mathbf{L}}$ & $0.77(0.08)$ & $2.92(0.23)$ & $16.66(1.72)$ & $0.73(0.09)$ & $2.78(0.25)$ & $31.50(0.37)$ \\
\hline $\mathbf{r}^{2}$ & 0.989 & 0.991 & 0.998 & 0.969 & 0.996 & 0.977 \\
\hline \multirow{2}{*}{ Parameters } & \multicolumn{3}{|c|}{$\mathbf{H g}^{2+}$ (single-component) } & \multicolumn{3}{|c|}{$\mathrm{Hg}^{2+}$ (multi-component) } \\
\hline & Imogolite & nZVI & Imo-nZVI & Imogolite & nZVI & Imo-nZVI \\
\hline qmax & $56.99(5.92)$ & $62.08(6.61)$ & $72.66(7.22)$ & $49.76(7.22)$ & $56.00(7.22)$ & $61.58(7.22)$ \\
\hline $\mathbf{K}_{\mathbf{L}}$ & $0.74(0.07)$ & $5.55(0.48)$ & $21.71(3.01)$ & $0.93(0.11)$ & $7.84(0.80)$ & $54.02(5.98)$ \\
\hline $\mathbf{r}^{2}$ & 0.990 & 0.993 & 0.979 & 0.974 & 0.996 & 0.987 \\
\hline
\end{tabular}

808

809

810

811

812

813

814

815

816

817

818

819

820

821

822

823 
828 Estefanía M. Martinis ${ }^{\text {a*, Juliano C. Denardin }}{ }^{\mathrm{b}}$, Raul Calderón ${ }^{\mathrm{c}, \mathrm{d}}$, Cristóbal Flores ${ }^{\mathrm{e}}$,

829 Karen Manquián-Cerda ${ }^{\mathrm{e}}$, Tamara Maldonado ${ }^{\mathrm{e}}$, Nicolás Arancibia-Miranda ${ }^{\mathrm{b}, \mathrm{e} *}$

$830{ }^{a}$ Facultad de Ingeniería, Universidad Nacional de Cuyo, Consejo Nacional de

831 Investigaciones Científicas y Técnicas, UNCUYO-CONICET, Mendoza, Argentina

$832{ }^{b}$ Center for the Development of Nanoscience and Nanotechnology, CEDENNA, Santiago,

833 Chile

$834{ }^{c}$ Centro de Investigación en Recursos Naturales y Sustentabilidad, Universidad Bernardo

835 O’Higgins, Fabrica, 1990, Segundo Piso, Santiago, Chile

836 Instituto de Investigaciones Agropecuarias, INIA La Platina, Santa Rosa, 11610,

837 Santiago, Chile

$838{ }^{e}$ Facultad de Química y Biología, Universidad de Santiago de Chile, Santiago, Chile

$839 *$ *Corresponding authors. Tel.: +56 2 7181048; fax: +56 227181048

840 E-mail address: nicolas.arancibia@usach.cl (N. Arancibia-Miranda)

841 emartinis@mendoza-conicet.gob.ar (Estefanía M. Martinis)

842

843 


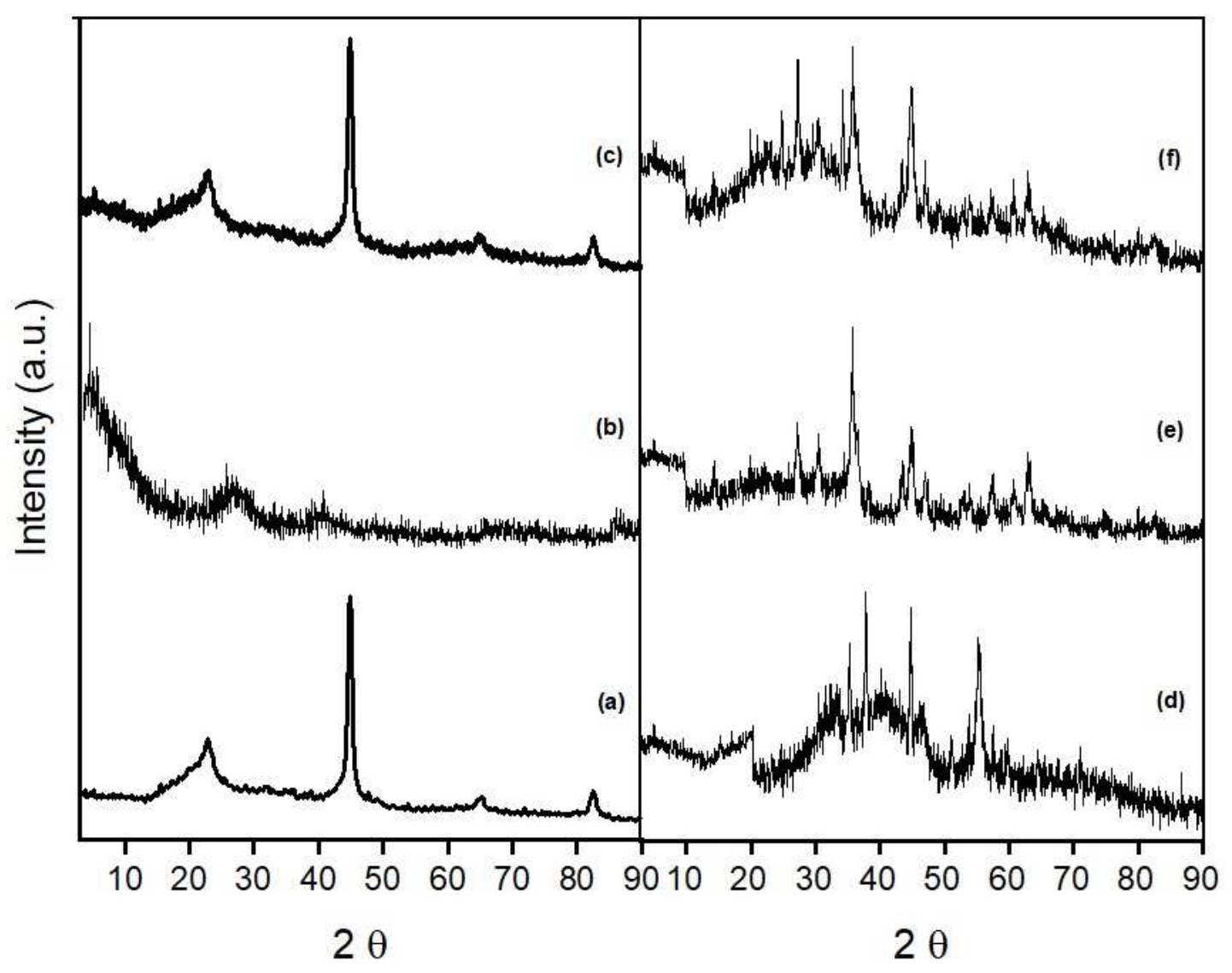

844

845 Fig S1. X-ray diffraction of imogolite (a), nZVI (b), Imo-nZVI (c), Imo-nZVI/Pb (d),

846 Imo-nZVI/Hg (e), and Imo-nZVI/Pb-Hg (f).

847

848

849

850

851

852

853 

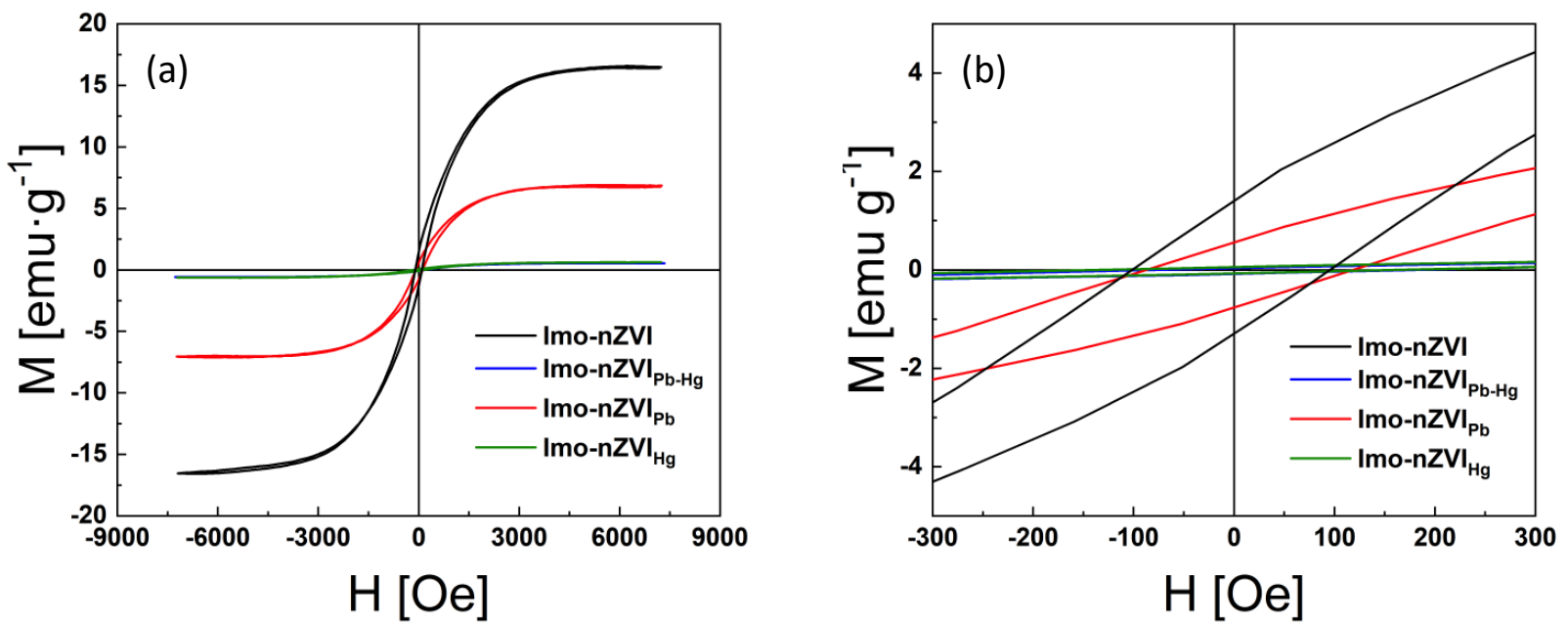

855 Fig S2. Hysteresis curve of Imo-nZVI pre- and post-sorption of $\mathrm{Hg}, \mathrm{Pb}$ and $\mathrm{Pb}-\mathrm{Hg}(\mathrm{a})$.

856 Enlargement of the magnetization curves (b).

857

858 
Table S1. Speciation curve

\begin{tabular}{ccc} 
Species & Log K & $\begin{array}{c}\text { Conc. } \\
{[\mathbf{m o l} / \mathbf{l}]}\end{array}$ \\
\hline Hg2++ & $0.000 \mathrm{E} 0$ & 0,182 \\
Hg2OH+ & -4900 & 0,00228 \\
K+ & $0.000 \mathrm{E} 0$ & 9,93 \\
KOH & -14500 & $3,13 \mathrm{E}-11$ \\
KNO3 & -150 & 0,0696 \\
NO3- & $0.000 \mathrm{E} 0$ & 9,91 \\
$\mathbf{P b + +}$ & $0.000 \mathrm{E} 0$ & 0,158 \\
$\mathbf{P b O H +}$ & -7700 & 0,00000314 \\
$\mathbf{P b}(\mathbf{O H}) 2$ & -17100 & $1,25 \mathrm{E}-12$ \\
$\mathbf{P b}(\mathbf{O H}) 3-$ & -28100 & $1,24 \mathrm{E}-20$ \\
$\mathbf{P b 2 O H + + +}$ & -6400 & $9,87 \mathrm{E}-09$ \\
$\mathbf{P b 3}(\mathbf{O H}) 4++$ & -23900 & $4,89 \mathrm{E}-21$ \\
$\mathbf{P b 4}(\mathbf{O H}) 4++++$ & -20900 & $7,71 \mathrm{E}-22$ \\
$\mathbf{P b 6}(\mathbf{O H}) 8++++$ & -43600 & $3,79 \mathrm{E}-40$ \\
$\mathbf{P b N O 3 +}$ & 1170 & 0,0231 \\
$\mathbf{P b}(\mathbf{N O 3}) 2$ & 1400 & 0,000389 \\
$\mathbf{O H}-$ & -14000 & $9,98 \mathrm{E}-09$ \\
$\mathbf{H +}$ & $0.000 \mathrm{E} 0$ & 1 \\
\hline
\end{tabular}

862

863

864

865

866

867 Table S2. $\Delta \mathrm{G}$ values for the studied materials. 


\begin{tabular}{|c|c|c|c|c|c|c|}
\hline \multirow{2}{*}{ Parameters } & \multicolumn{3}{|c|}{$\mathrm{Pb}^{2+}$ (single component) } & \multicolumn{3}{|c|}{$\mathrm{Pb}^{2+}$ (multi component) } \\
\hline & Imogolite & nZVI & Imo-nZVI & Imogolite & nZVI & Imo-nZVI \\
\hline$\Delta G\left(J \cdot \mathrm{mol}^{-1}\right) \times 10^{3}$ & -45.2 & -50.2 & -54.5 & -45.3 & -48.6 & -52.9 \\
\hline \multirow{2}{*}{ Parameters } & \multicolumn{3}{|c|}{$\mathrm{Hg}^{2+}$ (single component) } & \multicolumn{3}{|c|}{$\mathrm{Hg}^{2+}$ (multi component) } \\
\hline & Imogolite & nZVI & Imo-nZVI & Imogolite & nZVI & Imo-nZVI \\
\hline$\Delta G\left(J \cdot \mathrm{mol}^{-1}\right) \times 10^{3}$ & -45.7 & -51.0 & -55.8 & -45.1 & -48.4 & -53.5 \\
\hline
\end{tabular}

868

869

870

871

872

873

874

875

876

877

878

879

880

881

882 
Figures

Fig. 1
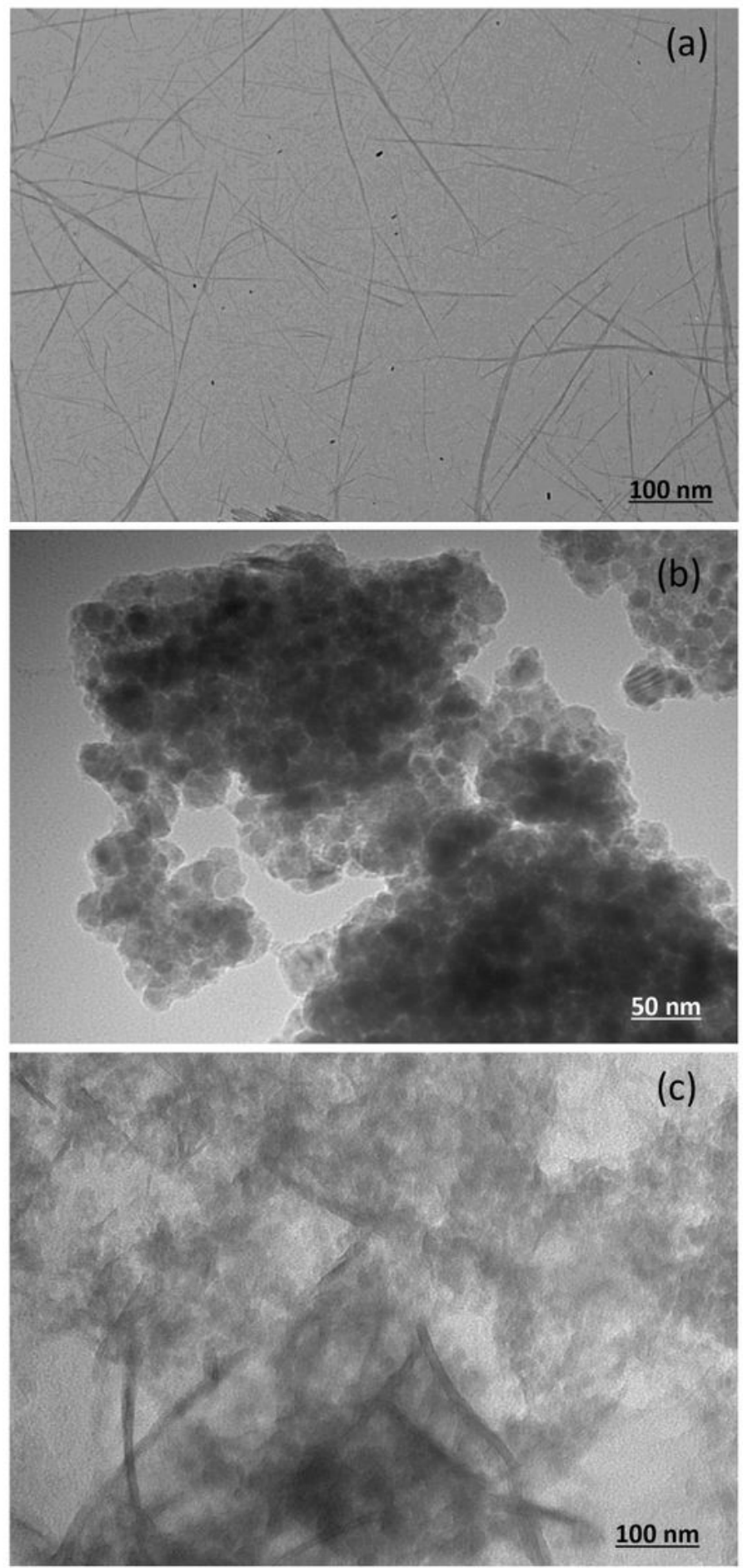

Figure 1

Morphology of the samples obtained by HR-TEM. 
Fig. 2

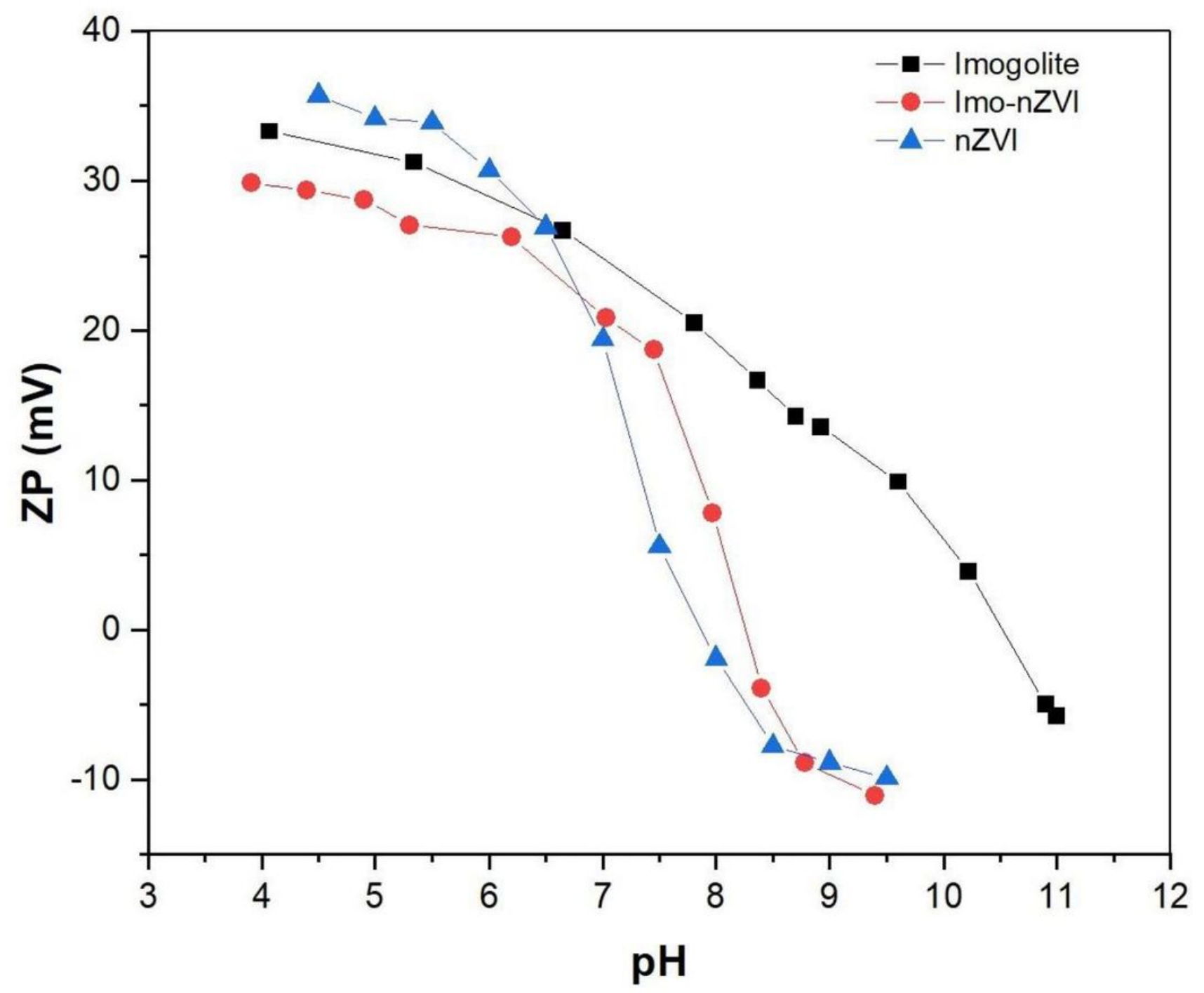

Figure 2

ZP vs. pH plot of synthetic Imo, nZVI, and Imo-nZVI. 
Fig. 3
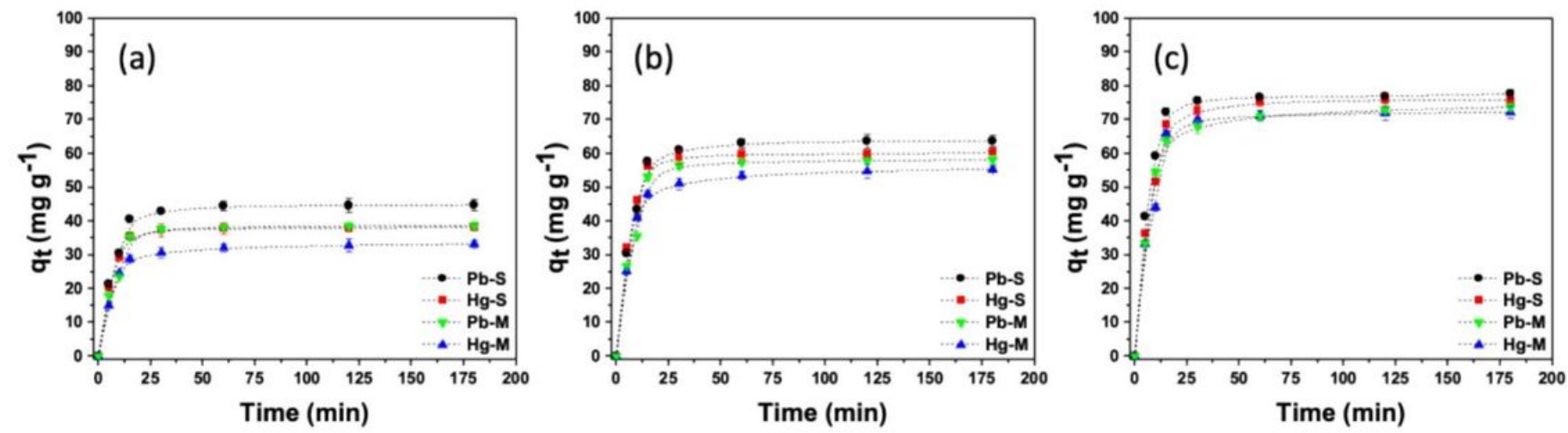

Figure 3

Effect of contact time on the removal of heavy metals from each sample.

Fig. 4
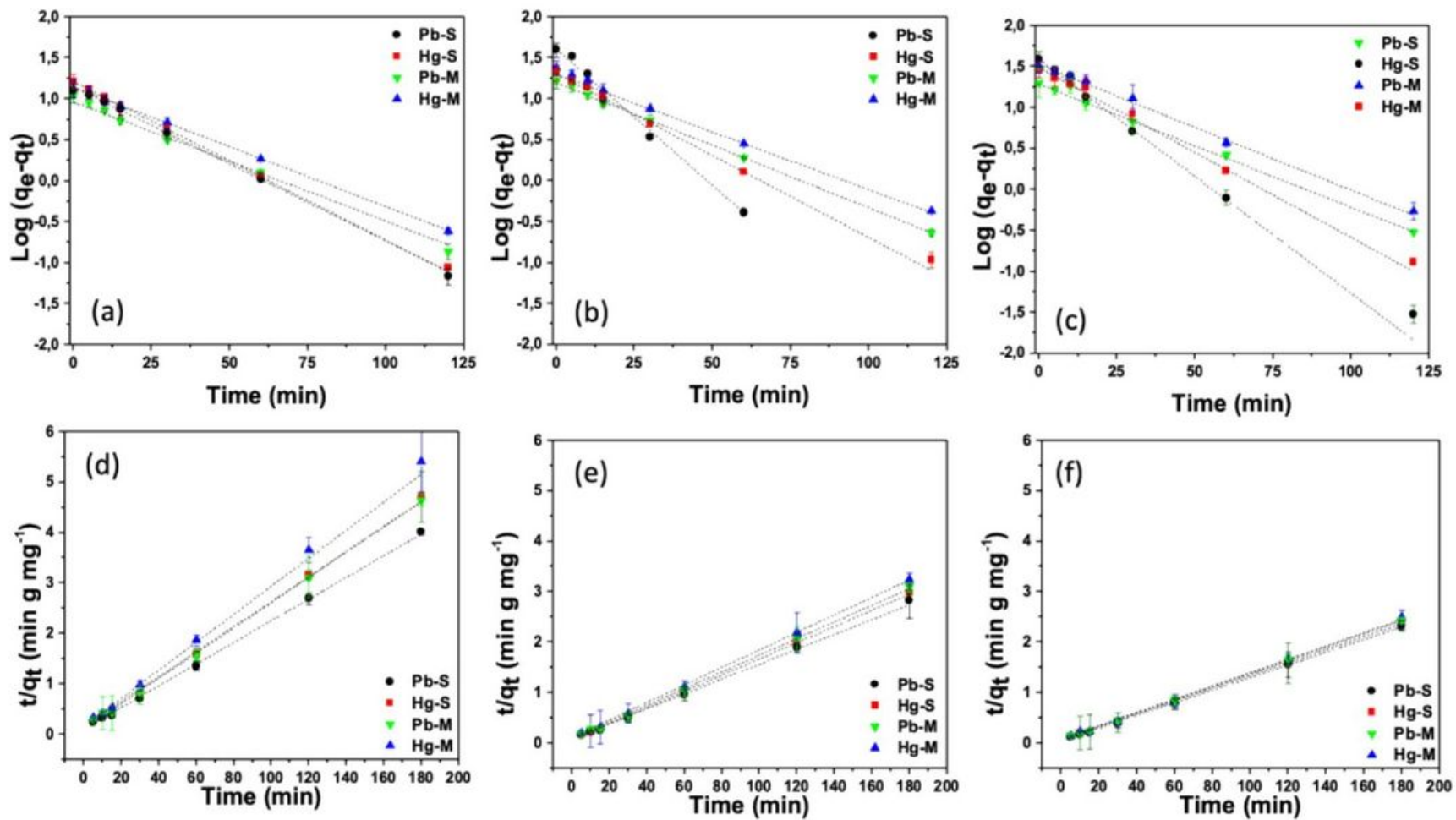

Figure 4 
Kinetic models of pseudo first-order (PFO) for (a) Imo, (b) nZVI, and (c) Imo-nZVI and pseudo secondorder (PSO) for (d) Imo, (e) nZVI, and (f) Imo-nZVI.

Fig. 5
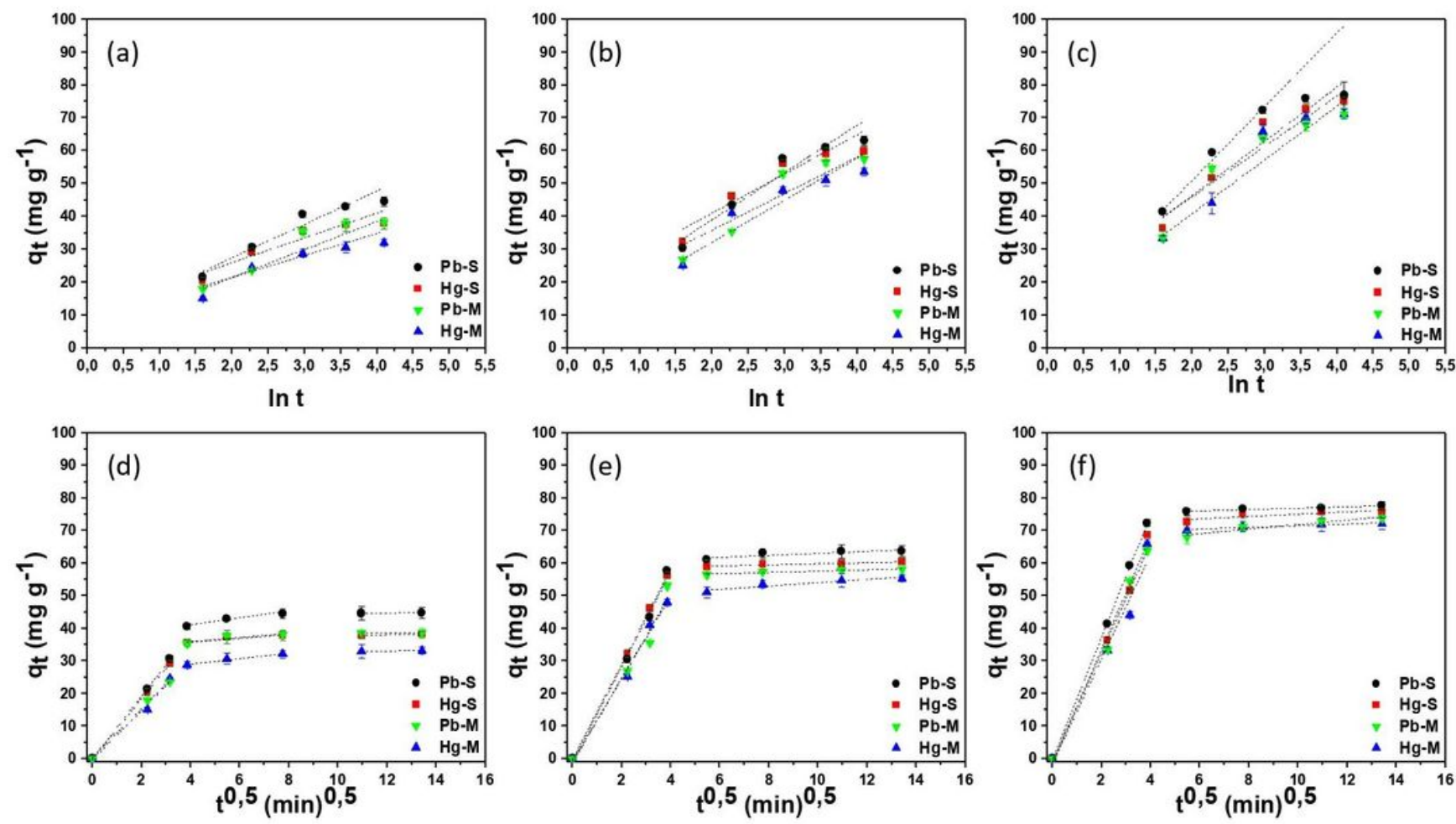

\section{Figure 5}

Fits of the experimental data to the Elovich equation for (a) imogolite, (b) nZVI, and (c) Imo-nZVI and Weber-Morris model for (d) Imo, (e) nZVI, and (f) Imo-nZVI.

Fig. 6
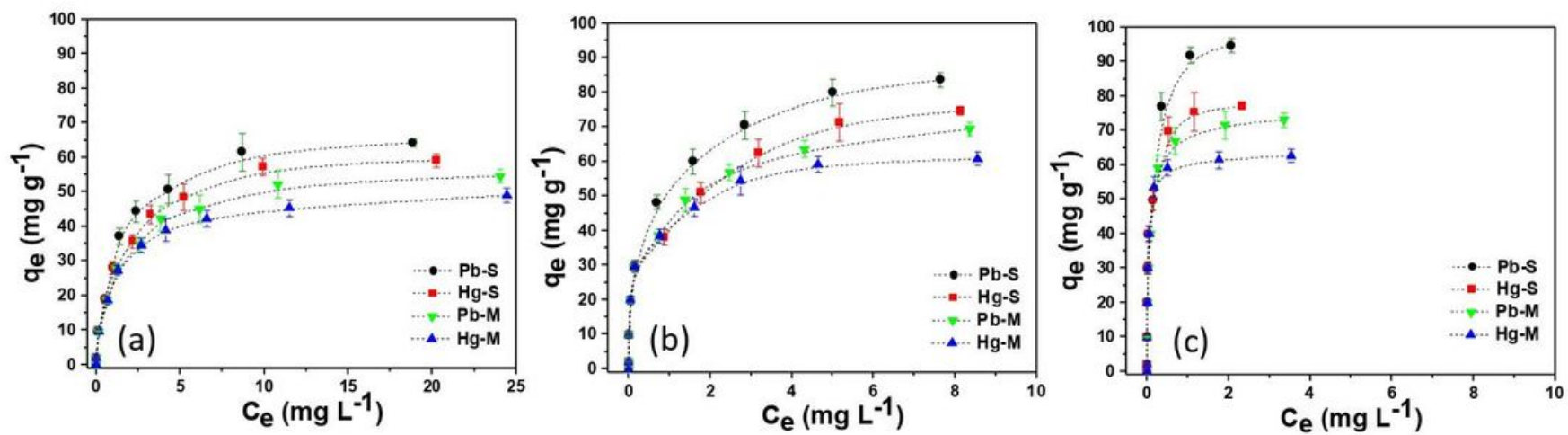


\section{Figure 6}

Langmuir isotherm for the adsorption of $\mathrm{Pb} 2+$ and $\mathrm{Hg} 2+$ in single $(\mathrm{S})$ and multicomponent $(\mathrm{M})$ systems on nZVI, Imo, and Imo-nZVI.

Fig. 7

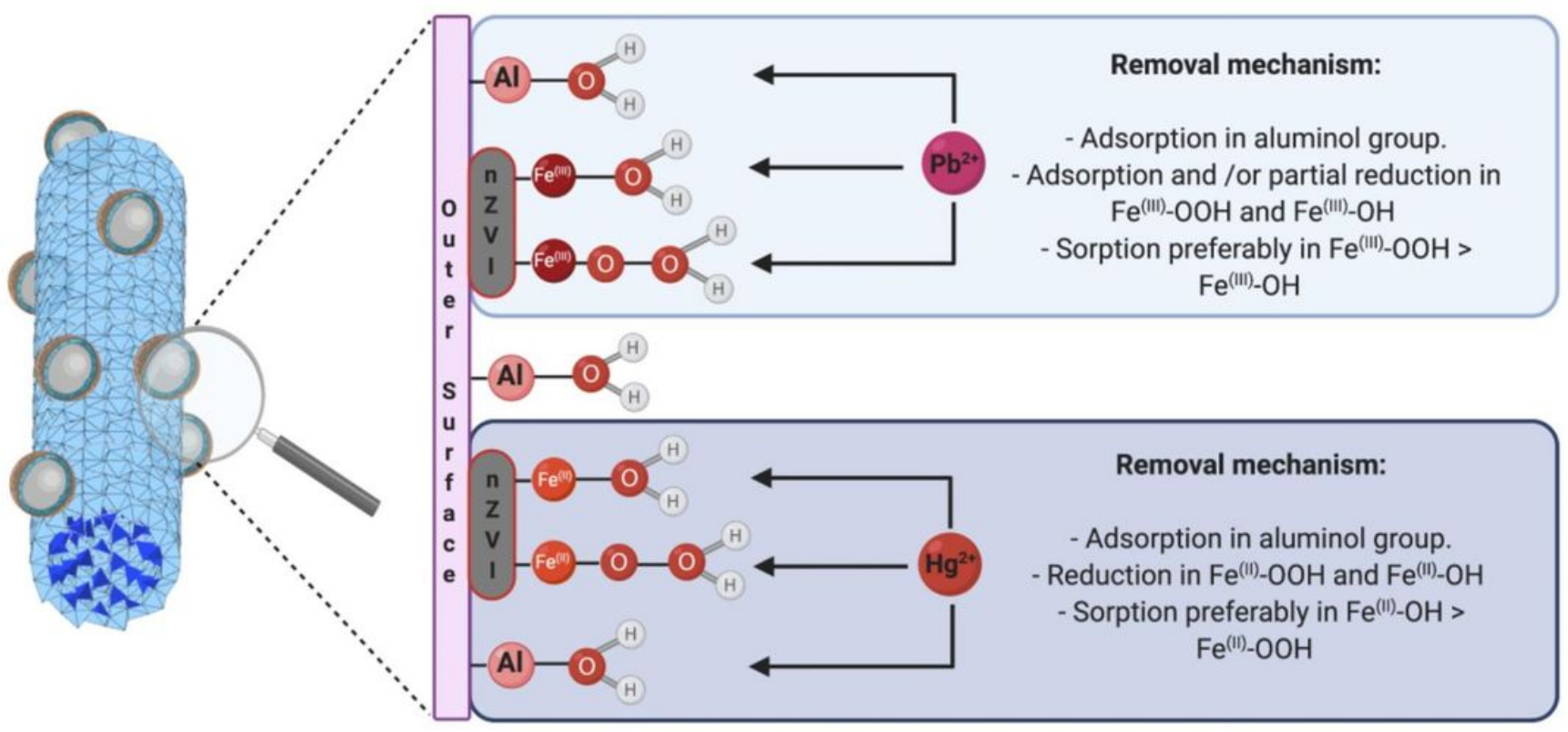

Figure 7

Schematic representation of the possible interactions that occur on the surface of the Imo-nZVI. The affinity and intensity of removal of $\mathrm{Pb} 2+$ and $\mathrm{Hg} 2+$ with the different groups of the nanocomposite is conditioned by the magnitude of the Misono softness parameters ( $\mathrm{YHg} 2+=4.24$ and $\mathrm{YPb} 2+=3.58$ ) and the possibility they have of interacting with functional groups with similar characteristics.

\section{Supplementary Files}

This is a list of supplementary files associated with this preprint. Click to download.

- S1.jpg

- S2.jpg 